\title{
Greenhouse gas profiling by infrared-laser and microwave occultation: retrieval algorithm and demonstration results from end-to-end simulations
}

\author{
V. Proschek, G. Kirchengast, and S. Schweitzer \\ Wegener Center for Climate and Global Change (WEGC) and Institute for Geophysics, Astrophysics and \\ Meteorology/Institute of Physics (IGAM/IP), University of Graz, Graz, Austria
}

Received: 8 March 2011 - Published in Atmos. Meas. Tech. Discuss.: 21 April 2011

Revised: 25 August 2011 - Accepted: 28 August 2011 - Published: 4 October 2011

\begin{abstract}
Measuring greenhouse gas (GHG) profiles with global coverage and high accuracy and vertical resolution in the upper troposphere and lower stratosphere (UTLS) is key for improved monitoring of GHG concentrations in the free atmosphere. In this respect a new satellite mission concept adding an infrared-laser part to the already well studied microwave occultation technique exploits the joint propagation of infrared-laser and microwave signals between Low Earth Orbit (LEO) satellites. This synergetic combination, referred to as LEO-LEO microwave and infrared-laser occultation (LMIO) method, enables to retrieve thermodynamic profiles (pressure, temperature, humidity) and accurate altitude levels from the microwave signals and GHG profiles from the simultaneously measured infrared-laser signals. However, due to the novelty of the LMIO method, a retrieval algorithm for GHG profiling is not yet available. Here we introduce such an algorithm for retrieving GHGs from LEO-LEO infraredlaser occultation (LIO) data, applied as a second step after retrieving thermodynamic profiles from LEO-LEO microwave occultation (LMO) data. We thoroughly describe the LIO retrieval algorithm and unveil the synergy with the LMOretrieved pressure, temperature, and altitude information. We furthermore demonstrate the effective independence of the GHG retrieval results from background (a priori) information in discussing demonstration results from LMIO end-toend simulations for a representative set of GHG profiles, including carbon dioxide $\left(\mathrm{CO}_{2}\right)$, water vapor $\left(\mathrm{H}_{2} \mathrm{O}\right)$, methane $\left(\mathrm{CH}_{4}\right)$, and ozone $\left(\mathrm{O}_{3}\right)$. The GHGs except for ozone are well
\end{abstract}

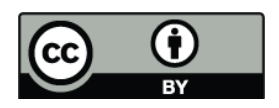

Correspondence to: V. Proschek (veronika.proschek@uni-graz.at) retrieved throughout the UTLS, while ozone is well retrieved from about $10 \mathrm{~km}$ to $15 \mathrm{~km}$ upwards, since the ozone layer resides in the lower stratosphere. The GHG retrieval errors are generally smaller than $1 \%$ to $3 \%$ r.m.s., at a vertical resolution of about $1 \mathrm{~km}$. The retrieved profiles also appear unbiased, which points to the climate benchmarking capability of the LMIO method. This performance, found here for clear-air atmospheric conditions, is unprecedented for vertical profiling of GHGs in the free atmosphere and encouraging for future LMIO implementation. Subsequent work will examine GHG retrievals in cloudy air, addressing retrieval performance when scanning through intermittent upper tropospheric cloudiness.

\section{Introduction}

The LEO-LEO microwave and infrared-laser occultation (LMIO) method is a thoroughly defined synergistic combination of LEO-LEO microwave occultation (LMO) and LEO-LEO infrared-laser occultation (LIO), as schematically shown in Fig. 1 and introduced in detail by Kirchengast et al. (2010a), Schweitzer (2010), and Kirchengast and Schweitzer (2011). This proposed inter-satellite active limb sounding technique would enable the synergy of deriving thermodynamic variables, including pressure, temperature and humidity, from LMO phase and amplitude data, and at the same time trace species concentrations and the line-of-sight wind speed from LIO intensity data. The primary altitude domain of the measurements is the upper troposphere and lower stratosphere (UTLS; $\sim 5 \mathrm{~km}$ to $35 \mathrm{~km}$ ) where all main greenhouse gases (GHGs) except the synthetic

Published by Copernicus Publications on behalf of the European Geosciences Union. 


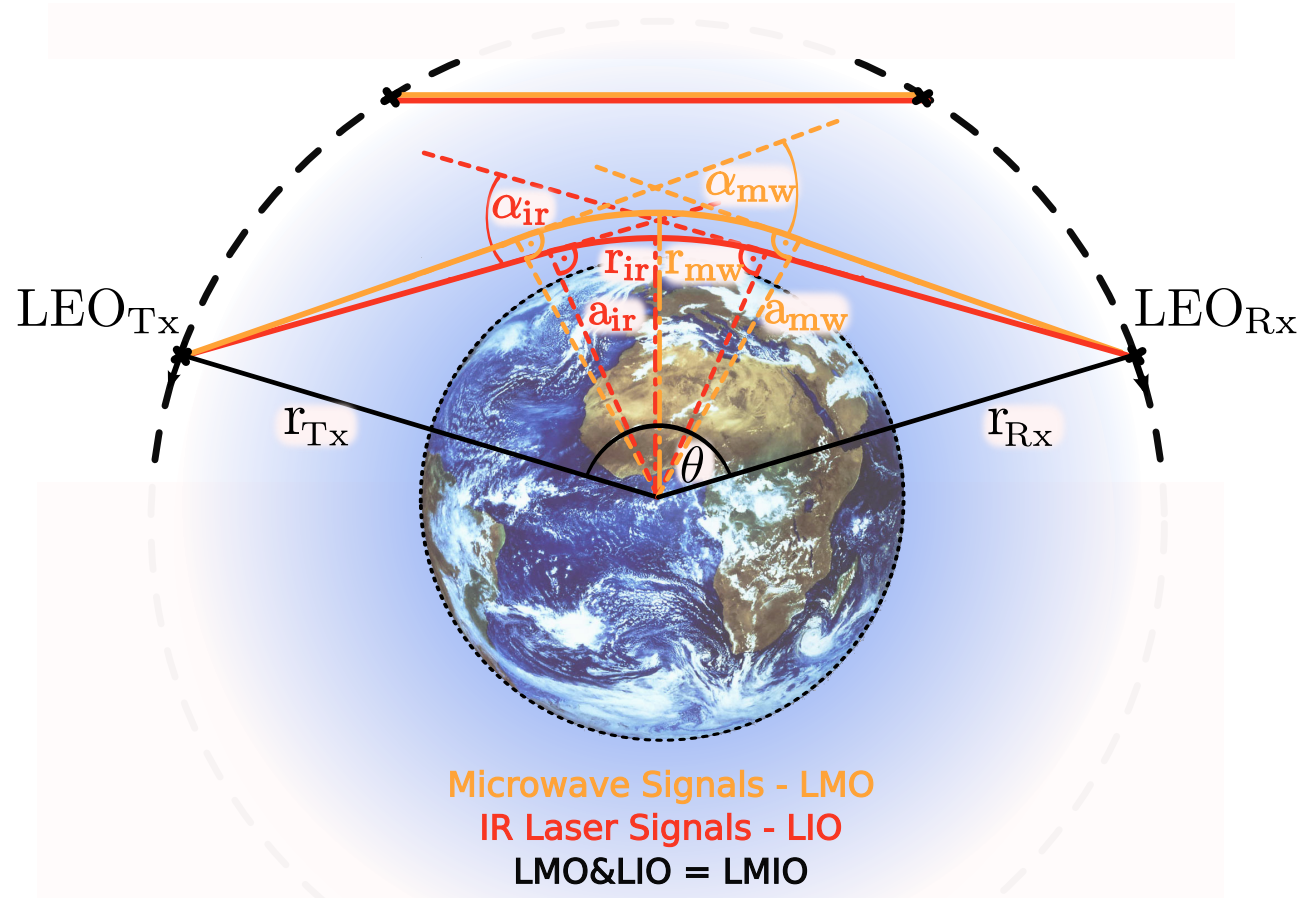

Fig. 1. Schematic view of the LEO-LEO microwave and infrared-laser occultation (LMIO) measurement geometry, as a combination of LMO signals (MW, orange signal paths) and LIO signals (IR, red signal paths) which pass the vacuum as straight lines and are refracted by the atmosphere. Characteristic MW and IR parameters defining this geometry are marked; see the text in Sect. 2.1 for further explanation.

chlorine-flourine-containing species can be retrieved, i.e., water vapor, carbon dioxide, methane, nitrous oxide, ozone, and carbon monoxide.

As described by Kirchengast and Schweitzer (2011), the LMIO method can be considered as a next generation of the well established and successful GNSS-LEO radio occultation (GRO) method (Ware et al., 1996; Kursinski et al., 1997; Steiner et al., 2001; Anthes et al., 2008; Luntama et al., 2008; Steiner et al., 2009; Ho et al., 2009). LMIO and GRO share the occultation measurement principle (Phinney and Anderson, 1968; Kirchengast, 2004) and the use of highly coherent and stable inter-satellite signals, and therefore the potential of providing accurate, long-term, consistent benchmark data with high vertical resolution and global coverage. However, while GRO uses decimeter-wave navigation signals from the Global Positioning System GPS, and of other future navigation satellites, LMIO will use specifically developed centimeter- and millimeter-wave (LMO) and micrometerwave signals (LIO). These vastly expand the accessible atmospheric variables from the GRO focus on refractivityrelated variables to the full suite of thermodynamic, composition, and wind variables noted above (for more details see Kirchengast and Schweitzer, 2011).
The LMO part of LMIO has substantial heritage from a range of studies over the recent decade (Kursinski et al., 2002, 2009; Herman et al., 2004; Kirchengast and Hoeg, 2004; Gorbunov and Kirchengast, 2005, 2007) and very recently a detailed LMO algorithm description and performance analysis was provided by Schweitzer et al. (2011b). This heritage work established well the expected performance of LMO for accurate thermodynamic state profiling in the UTLS, which serves as the basis for the LIO-related GHG profiling introduced here.

We implemented the LIO retrieval as a complementary, subsequent part to the LMO retrieval of Schweitzer et al. (2011b), completing the LMIO retrieval algorithm introduced in a brief overview form in Kirchengast and Schweitzer (2011). We describe in this study the detailed steps of the algorithm, which can be applied for single species (single-line trace species retrieval, SSR) or a set of several trace species (multi-line trace species retrieval, MSR), and include a demonstration of its capabilities by endto-end performance simulation results. The synergy between LMO and LIO is pointed out, since the LMO retrieval with its thermodynamic profiles as output serves as a necessary provider of input information for the LIO retrieval. In addition, the effective independence from external (a priori) 
information and the high accuracy of the LIO retrieval results, i.e., of the GHG and isotope profiles, is emphasized.

The paper is structured as follows. We start with introducing the geometry, the main atmospheric effects relevant to the retrieval algorithm, and the simulation and retrieval demonstration setup in Sect. 2. This preparatory information is followed by a detailed LIO algorithm description in Sect. 3, describing the core elements and necessary systematic update loops over the core. In Sect. 4 the demonstration results are discussed. Finally, Sect. 5 presents a summary and conclusions of the study.

\section{Geometry and setup}

\subsection{Geometry and atmospheric effects}

Figure 1 illustrates the LMO and LIO signal propagation paths, with all signals transmitted from one joint platform, $\mathrm{LEO}_{\mathrm{Tx}}$, and received at another joint platform, $\mathrm{LEO}_{\mathrm{Rx}}$. Both LMO and LIO signals follow closely similar but not identical paths, i.e., the refraction becomes somewhat different for the microwave (MW) and infrared (IR) signals, proportional to the amount of water vapor in the air (Thayer, 1974; Bönsch and Potulski, 1998; Kirchengast and Schweitzer, 2011; Schweitzer et al., 2011a). The corresponding difference in bending of MW and IR ray paths is practically negligible above about $8 \mathrm{~km}$ to $12 \mathrm{~km}$, a highly favorable property, and gradually increases downwards into the troposphere (Schweitzer et al., 2011a), leading to a difference of the tangent altitudes of about $0.5 \mathrm{~km}$ near $5 \mathrm{~km}$ in moist conditions (Kirchengast et al., 2010a).

Figure 1 highlights that this different bending of MW and IR rays, despite generally being a very small effect, formally leads to different bending angles $\left(\alpha_{\mathrm{MW}}, \alpha_{\mathrm{IR}}\right)$ at any given time during an occultation event and as well also to different impact parameters $\left(a_{\mathrm{MW}}, a_{\mathrm{IR}}\right)$ and radial distances from the center of curvature to the tangent points $\left(r_{\mathrm{MW}}, r_{\mathrm{IR}}\right)$, the latter implying as well different tangent point altitudes. The radial distances from the center of curvature to the satellite platforms are given by $r_{\mathrm{Tx}}$ and $r_{\mathrm{Rx}}$, with $\theta$ being the opening angle between the two satellite vectors. This geometric setup of the LIO signal propagation on top of the LMO signal propagation is, in addition to the LMO heritage summarized in the introduction, a key basis for formulating the LIO-related GHG profiling algorithm.

The influences of absorption by atmospheric trace species and of other atmospheric processes on the carefully selected quasi-monochromatic LIO signals are essential for the LIO method. Besides the absorption of the target greenhouse gas, also other influences due to the atmospheric background such as defocusing, foreign species absorption, Rayleigh scattering, aerosol extinction, cloud extinction, signal scintillations from turbulence, Doppler shift of signal frequencies due to line-of-sight winds, and Rayleigh as well as cloud scattering of solar radiation into the receiver are potentially relevant. The effects from these background influences, except for cloud extinction, are practically either negligibly small under most conditions or can be reduced to very small levels of residual error (typically $<0.1 \%$ ) as discussed by other studies (Emde and Proschek, 2010; Schweitzer, 2010; Kirchengast et al., 2010a; Schweitzer et al., 2011a). In the LIO forward simulations of the received intensity signals for this study we account for the main effects of attenuation, namely target and foreign species absorption, and defocusing (plus for the small Rayleigh scattering loss since easily comodeled). Cloudy air and a suitable retrieval will be treated in a separate study; a brief discussion of cloud influences, including limitations to tropospheric penetration of part of the events especially in the tropics, is given by Schweitzer et al. (2011a). The other effects can be assumed negligible, or are sufficiently corrected to the level of thermal noise that we include. This is sufficient in the context here to demonstrate the new retrieval algorithm.

To isolate the absorption due to the target GHG from the absorption of foreign species and broadband atmospheric effect, an adjacent pair of signals, one "absorption signal" (at the center of an absorption line of a target species) and one "reference signal" (off-line of any trace species absorption) is employed using a differential absorption principle (Kursinski et al., 2002; Gorbunov and Kirchengast, 2007; Kirchengast et al., 2010a; Kirchengast and Schweitzer, 2011; Schweitzer et al., 2011a), which will be explained in detail in Sect. 3 . In the retrieval presented in Sects. 3 and 4, the target species $\mathrm{H}_{2} \mathrm{O}, \mathrm{CO}_{2}, \mathrm{CH}_{4}, \mathrm{O}_{3}, \mathrm{~N}_{2} \mathrm{O}$, and $\mathrm{CO}$ are specifically taken into account, with focus on the first four. But we note that the retrieval algorithm itself is generically valid for any group of LIO target species.

\subsection{Simulation and retrieval demonstration setup}

For the simulation of the LMIO measurements, which we produced for demonstrating the new retrieval algorithm, we used the End-to-End Generic Occultation Performance Simulation and Processing System (EGOPS5.5) and the eXperimental End-to-End Generic Occultation Performance Simulation and Processing System (xEGOPS5.5) (Fritzer et al., 2009, 2010). The EGOPS system development started for GRO end-to-end simulations more than a decade ago (Kirchengast, 1996, 1998; Ramsauer and Kirchengast, 2000; Kirchengast et al., 2002), was then extended to also enable LMO simulations (Kirchengast et al., 2007; Fritzer et al., 2009), and proved useful in a myriad of GRO and LMOrelated studies, including the recent study by Schweitzer et al. (2011b). The complementary xEGOPS system (Fritzer et al., 2010) was developed more recently and extends EGOPS by LIO end-to-end simulation capabilities. We use EGOPS/xEGOPS here in the same way and logic for LMIO simulations as Schweitzer et al. (2011b) used EGOPS for LMO simulations. 
We start with the Mission Analysis Planning (MAP), a subsystem of EGOPS, to generate occultation events for a low-, mid- and high latitude region for 15 July 2007 (an arbitrary example day). We used LEO satellites in sun-synchronous orbits, two transmitters and two counterrotating receivers, with the transmitters at an orbital height of $800 \mathrm{~km}$ and the receivers at $650 \mathrm{~km}$, yielding about 230 globally well distributed occultation events per day (same as Schweitzer et al., 2011b). The MAP calculates occultation event locations and related positions of the transmitter and receiver satellites during the event. The occultation events chosen for further forward modeling are a tropical (TRO, $1.3^{\circ} \mathrm{N} / 55.6^{\circ} \mathrm{W}$ ), a standard (STD, $38.0^{\circ} \mathrm{N} / 71.2^{\circ} \mathrm{W}$ ) and a sub-arctic winter event (SAW, $72.8^{\circ} \mathrm{S} / 13.7^{\circ} \mathrm{E}$ ), together allowing to span a representative range of atmospheric conditions.

The Forward Modeling (FOM) subsystem of EGOPS/xEGOPS uses the MAP results (satellite positions and velocities) to simulate excess phase, amplitude (LMO) and intensity (LIO) profiles as a function of time for each occultation event. For the simulation of realistic ray paths a highly accurate geometric optical ray-tracing algorithm is used at a sampling rate of $10 \mathrm{~Hz}$ (Syndergaard, 1999). We assume spherical symmetry of the atmosphere about the occultation event location (to avoid including representativeness errors; cf. Schweitzer et al., 2011b) and an ellipsoidal Earth shape (WGS84, Fuchs and Stoffel, 1984). The ray-tracing uses for the LMO channels the microwave refractivity formula of Smith and Weintraub (1953) and for the LIO channels an accurate but simplified approximation of the visible/infrared refractivity formula by Bönsch and Potulski (1998) (more details in Sect. 3.3). Absorption by trace species is integrated along these ray paths. The relevant absorption coefficients for the LMO channels are computed by an advanced version of Liebe's Millimeter Wave Propagation Model MPM93 (Liebe et al., 1993; Schweitzer et al., 2011b), those for the LIO channels by the Reference Forward Model (RFM) (Edwards, 1996; Dudhia, 2008), which uses the spectroscopic parameters from the HITRAN2004 database (Rothman et al., 2005).

The atmospheric model used is the Fast Atmospheric Signature Code (FASCODE) model (in the form supplied online by FASCODE, 2008), including the US standard atmosphere (Anderson et al., 1986). In line with the latitudes of occultation events selected above we use the tropical (TRO), standard (STD), and sub-arctic winter (SAW) atmospheres (the STD atmosphere for the example cases illustrating the algorithm steps in Sects. 3.4 and 3.5, all three atmospheres for the demonstration results in Sect. 4). Each FASCODE atmosphere comprises profiles of the thermodynamic variables, namely pressure $(p)$, temperature $(T)$, and humidity $(q)$, as well as the concentration profiles of all needed trace species $\left(X=\left\{\mathrm{N}_{2} \mathrm{O}, \mathrm{CH}_{4},{ }^{12} \mathrm{CO}_{2},{ }^{13} \mathrm{CO}_{2}\right.\right.$, $\left.\mathrm{C}^{18} \mathrm{OO}, \mathrm{H}_{2} \mathrm{O}, \mathrm{HDO}, \mathrm{H}_{2}^{18} \mathrm{O}, \mathrm{CO}, \mathrm{O}_{3}\right\}$ ), where the concentrations of the secondary isotopes are estimated from the main isotope via isotopic fractional abundances following Rothman et al. (2005). The outdated FASCODE value for $\mathrm{CO}_{2}$ ( 330 ppmv up to about the mesopause) was updated to a more recent value of $380 \mathrm{ppmv}$ (see also Kirchengast and Schweitzer, 2011). The atmosphere is assumed to be free from clouds and aerosols (cf. discussion in Sect. 2.1); hence refraction, defocusing and GHG trace species absorption are the processes effectively contributing to the simulated LMO excess phase, LMO amplitude loss, and LIO intensity loss data (Rayleigh scattering loss is formally co-integrated along the rays but is negligible). The vertical simulation range is set to cover altitudes between $3 \mathrm{~km}$ and $80 \mathrm{~km}$. The frequency channels used for LMO are those of Schweitzer et al. (2011b) (5 channels, $17.25 \mathrm{GHz}, 20.2 \mathrm{GHz}, 22.6 \mathrm{GHz}, 179 \mathrm{GHz}$ and $182 \mathrm{GHz}$ ), the LIO channels used follow Schweitzer (2010) and Kirchengast and Schweitzer (2011) and are summarized in Table 1.

The simulation of quasi-realistic observation system errors is done with the EGOPS subsystem Observation System Modeling (OSM). Link budget computation accounting for transmitter power, free space loss, total atmospheric loss, and instrument-related losses are employed to model amplitude and intensity profiles in absolute terms (in $\mathrm{dBW}$ ) and to model thermal noise for adequate signal-to-noise ratios at the receiver $\left(67 \mathrm{dBHz} C / \mathrm{N}_{0}\right.$ for $\mathrm{LMO}$ amplitudes at top-of-atmosphere, $34 \mathrm{dBHz} \mathrm{SNR}$ for LIO intensities; cf. ?Schweitzer et al., 2011b; Kirchengast and Schweitzer, 2011). Residual linear drift errors over the occultation event, reflecting expected short-term stability limitations of measured LMO and LIO amplitudes/intensities, are superimposed as well; for LMO in the same way as by Schweitzer et al. (2011b), for LIO according to the system requirement specifications in Kirchengast et al. (2010a). Clock errors and precise-orbit-determination (POD) errors, affecting the LMO excess phase, and thermal noise on the phase are modeled in the same way as was done for GRO simulations by Steiner and Kirchengast (2005) and adopted for LMO simulations by Schweitzer et al. (2011b). Errors in spectroscopic parameters are not considered in this study because, on the one hand, they lead to essentially time-constant retrieval errors only with negligible effects on observing GHG variability and, on the other hand, their reduction is a separate matter of spectroscopic laboratory work. Kirchengast and Schweitzer (2011), section S2 therein, and Harrison et al. (2011) discuss the requirements and needs for reducing spectroscopic errors to within $\sim 0.1 \%$ in detail.

In order to finally provide the retrieved thermodynamic variables from LMO based on the simulated signals from the OSM subtool, we use the retrieval algorithm described by Schweitzer et al. (2011b), which is implemented in the Occultation Processing System (OPS) subsystem of EGOPS. As Schweitzer et al. (2011b) conclude, the LMO-retrieved thermodynamic profiles are essentially unbiased and achieve r.m.s. errors of $<0.2 \%$ for the pressure, $<0.5 \mathrm{~K}$ for the temperature and $<10 \%$ for the specific humidity; the related 
Table 1. Trace species retrieval order, associated absorption and reference wavenumbers, and their frequency spacing.

\begin{tabular}{clccc}
\hline $\begin{array}{c}\text { Retrieval } \\
\text { order }\end{array}$ & $\begin{array}{l}\text { Target species } \\
\text { [valid range] }\end{array}$ & $\begin{array}{c}\text { Absorption } \\
\text { wavenumber } \\
\mathrm{cm}^{-1}\end{array}$ & $\begin{array}{c}\text { Reference } \\
\text { wavenumber } \\
\mathrm{cm}^{-1}\end{array}$ & $\begin{array}{c}\text { (Abs-Ref)/Ref } \\
\text { freq. spacing } \\
\%\end{array}$ \\
\hline 1 & $\mathrm{~N}_{2} \mathrm{O}$ & 4710.340810 & 4731.03 & -0.4373 \\
2 & $\mathrm{CH}_{4}$ & 4344.163500 & 4322.93 & +0.4912 \\
3 & ${ }^{13} \mathrm{CO}_{2}$ & 4723.414953 & 4731.03 & -0.1610 \\
4 & $\mathrm{C}^{18} \mathrm{OO}$ & 4767.041369 & 4770.15 & -0.0652 \\
5 & $\mathrm{H}_{2} \mathrm{O}(1)[13-48 \mathrm{~km}]$ & 4204.840290 & 4227.07 & -0.5259 \\
6 & $\mathrm{H}_{2} \mathrm{O}(2)[8-25 \mathrm{~km}]$ & 4775.802970 & 4770.15 & +0.1185 \\
7 & $\mathrm{H}_{2} \mathrm{O}(3)[5-10 \mathrm{~km}]$ & 4747.054840 & 4731.03 & +0.3387 \\
8 & $\mathrm{H}_{2} \mathrm{O}(4)[4-8 \mathrm{~km}]$ & 4733.045010 & 4731.03 & +0.0426 \\
9 & $12 \mathrm{CO}$ & 4771.621441 & 4770.15 & +0.0308 \\
10 & $\mathrm{HDO}$ & 4237.016320 & 4227.07 & +0.2353 \\
11 & $\mathrm{H}_{2}^{18} \mathrm{O}$ & 4090.871800 & 4098.56 & -0.1876 \\
12 & $\mathrm{CO}$ & 4248.317600 & 4227.07 & +0.5027 \\
13 & $\mathrm{O}_{3}$ & 4029.109610 & 4037.21 & -0.2006 \\
\hline
\end{tabular}

altitude levels are determined to within $10 \mathrm{~m}$ accuracy. LMO is thus evidently very suitable to provide the needed thermodynamic state and altitude information to the LIO retrieval.

The LIO retrieval is then performed applying the OPS part of xEGOPS. It needs an array of initial/background GHG profiles as input. The latitude-dependent FASCODE GHG profiles are used for this purpose when demonstrating the single core steps of the SSR process in Sect. 3.4 and for the demonstration results in Sect. 4. The array is, for test purposes, also set to zero initial values for the GHG species $\mathrm{H}_{2} \mathrm{O}, \mathrm{CO}_{2}, \mathrm{CH}_{4}$ and $\mathrm{O}_{3}$ in the MSR process. This latter setting will demonstrate the importance of the order in which the trace species are retrieved, as discussed in Sect. 3.5.

\section{Retrieval algorithm}

In this section we discuss in detail the LIO retrieval algorithm, methodically supported by quasi-realistic end-to-end simulations. The main goal is to clearly describe the retrieval steps and processing flow and to show the utility of the combined LMO and LIO observations. We show the effective independence of the LMIO retrieval results from external/background/first guess information and demonstrate the high accuracy of the GHG profiles.

\subsection{Algorithm overview and context}

The retrieval flow of the LMO to the LIO variables is illustrated in Fig. 2, which visually emphasizes the synergy of LMO and LIO in the combined LMIO method.

In the left orange-bordered part of the scheme in Fig. 2, the LMO retrieval input (bright green), main calculation steps (orange) and final outputs (dark green) are shown. The detailed algorithm to derive the output variables from the LMO excess phase and amplitudes is described by Schweitzer et al. (2011b). The required variables of the LMO retrieval for the LIO retrieval are pressure $(p)$ and temperature $(T)$ on a given grid $(z)$, plus the MW impact parameter grid of the MW occultation rays that is associated with the original time grid of the transmitter and receiver positions. Since it is coavailable, we also formally use the humidity $(q)$ in computing the IR refractivity but because its contribution is practically negligible at UTLS altitudes in the IR domain (Bönsch and Potulski, 1998; Schweitzer, 2010) it could as well be disregarded.

The right red-bordered part of Fig. 2 illustrates the flow and inner-dependencies of the LIO SSR parameters. The direct LIO-observed input parameters are the received LIO intensity signals on the time grid shared with LMO signals and the transmitter and receiver positions. This input is complemented by first guess (initial/background) GHG profiles (bright green) used for convenience on the $z$ grid shared with $p, T$, and $q$ from LMO. From the MW impact parameter, combined with the thermodynamic variables, the "refractive" IR quantities are calculated (grey boxes), i.e., those quantities that are directly retrievable in the MW domain from the phase measurements but not from the IR intensity-only measurements.

Based on first preparing an auxiliary MW altitude grid as a function of time from the LMO input, these quantities include the IR refractivity (Bönsch and Potulski, 1998), followed by the IR impact parameter (cf. Bouguer's rule in Born and Wolf, 1964), the IR bending angle as auxiliary profile (using the Abel transform, e.g., Fjeldbo and Eshleman, 1965; Fjeldbo et al., 1971) and the IR tangent point altitude. These parameters are necessary to tie the LIO intensity signals measured as a function of time to their associated IR altitude levels (recall from Fig. 1 that the propagation path 


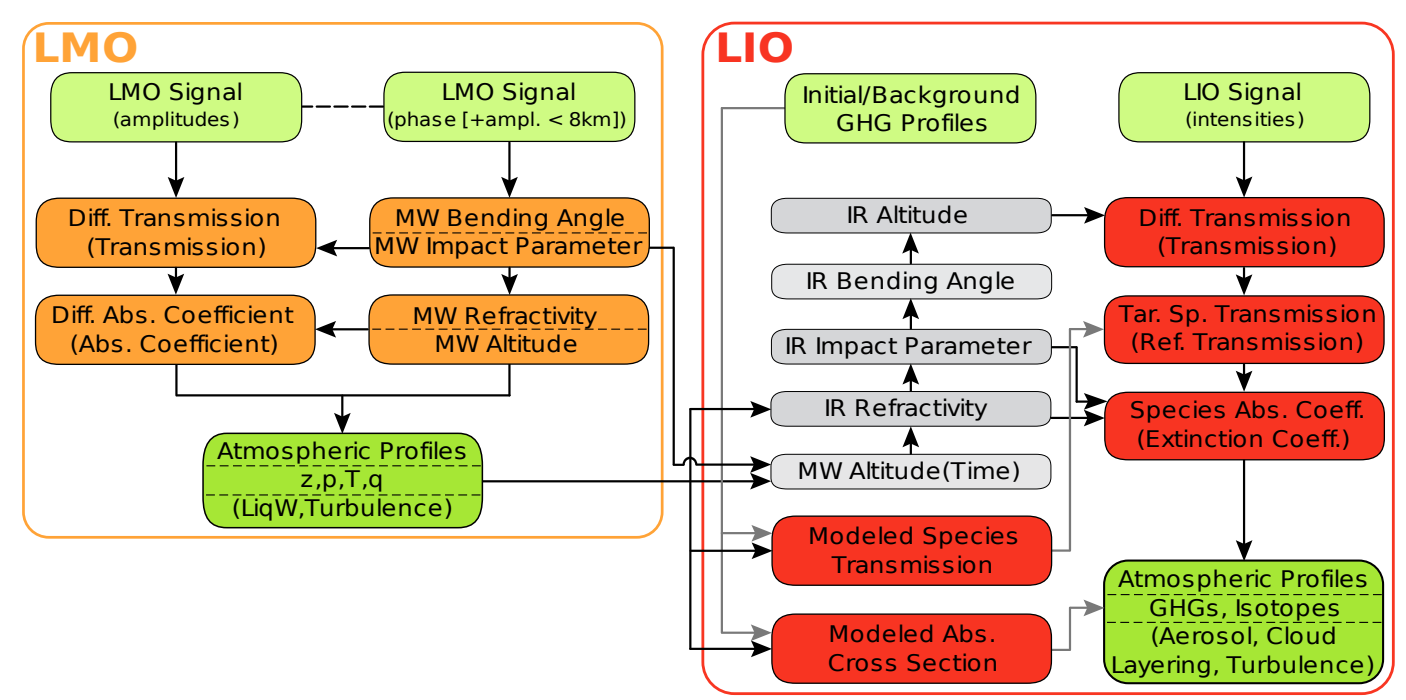

Fig. 2. Schematic overview of the LMIO retrieval processing system as implemented in the EGOPS/xEGOPS software, with its LMO (left, framed in orange) and LIO (right, framed in red) retrieval parts; see the text in Sect. 3.1 for further explanation.

differences between MW and IR occultation rays are essentially negligible in the stratosphere but need to be accounted for in the upper troposphere where humidity increases downwards, in order to ensure accurate retrievals within $20 \mathrm{~m}$ altitude geolocation accuracy down to $5 \mathrm{~km}$ ).

After the preparatory calculations of the "refractive" quantities, the core steps (red symbols in Fig. 2) of the SSR process are performed. First, a correction for defocusing loss is performed (an option not strictly needed if proceeding with differential transmissions) and the differential transmission is calculated from a pair of the LIO intensity profiles comprising one absorption and its corresponding reference channel (Table 1; Schweitzer, 2010; Kirchengast and Schweitzer, 2011), and the result allocated to the IR altitude grid. Subsequently, the differential transmission and the modeled species transmissions, which are derived by employing the RFM (Edwards, 1996; Dudhia, 2008) based on the initial/background GHG profiles, are used to isolate the target species transmission of the absorption channel. This target species transmission is the pure transmission due to a single GHG (e.g., ${ }^{12} \mathrm{CO}_{2}$ ), with effectively negligble influence of foreign species. The target species transmission is then used, together with the IR impact parameter and the IR refractivity, to retrieve the target species absorption coefficient on the IR altitude grid by use of the "absorptive" Abel transform (Kursinski et al., 2002; Schweitzer et al., 2011b). Finally, the GHG/isotope volume mixing ratio profile is derived from the target species absorption coefficient and a modeled absorption cross section of the target species for which we employ RFM based on the initial/background target species profile and the $p$ and $T$ profiles from LMO; likewise it could also be the mole fraction profile. Optionally, also the absolute concentrations of GHGs/isotopes could be computed as needed.

\subsection{Algorithm dynamic structure and flow}

While we focused above on an overview of the SSR core process of the LIO retrieval we focus in this subsection on an overview of the dynamic structure of the LIO algorithm before we then proceed to explain it step by step. Overall the LIO algorithm is a sequential order of retrieval calculation steps and two nested loops over the core retrieval algorithm as illustrated in Fig. 3. The input parameters are the retrieved LMO profiles, the LIO intensities and a set of initial/background GHG profiles as discussed above.

The first step in the LIO retrieval flow is to prepare the "refractive" quantities, where we then need IR refractivity, IR impact parameter, and IR altitude profiles (details in Sect. 3.3). The core part of the retrieval is then the SSR process (details in Sect. 3.4), which estimates the GHG/isotope profiles starting from the LIO intensity signals attributed to the IR impact parameter and IR altitude grid. This SSR core part is included in two nested loops, namely an inner MSR (multi-species retrieval) and an outer BUC (basic-updatecontrol) loop.

The inner MSR loop, an envelope process over the SSR process (details in Sect. 3.5), performs a carefully defined consecutive order of single species retrievals. After every single inner loop step, the initial/background GHG profiles are updated with the output from the SSR. This results in a step-wise improved set of GHG profiles. The order in which the species are retrieved is important; first the most independent species is retrieved (meaning the species which is derived from a channel pair which includes the smallest amount of foreign species absorption), followed by the other ones which are gradually more and more dependent on the target species already retrieved before. These are available to the later profiles as background profiles that have 


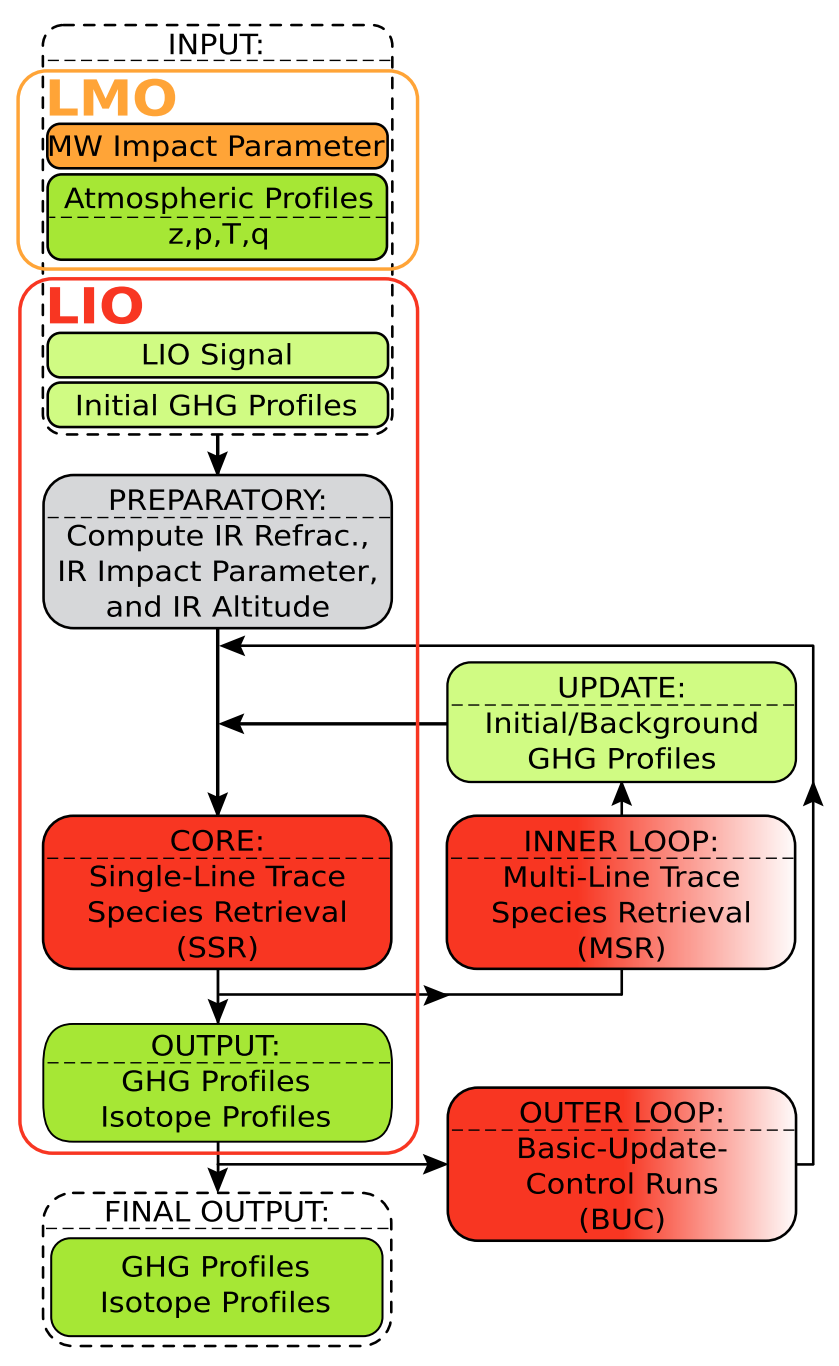

Fig. 3. Overview of the dynamic structure and flow of the LIO retrieval algorithm, highlighting its preparatory part, establishing IR refractivity, impact parameter, and altitude profiles (grey box), its core part, the single-line trace species retrieval SSR (red box), and its dynamical part of envelope loops over the SSR, consisting of the multi-line trace species retrieval (MSR) loop and the basicupdate-control run (BUC) loop, respectively (gradient-red boxes); see the text in Sect. 3.2 for further explanation.

already superseded the initial profiles in the array of initial/background GHG profiles. Additionally, in this MSR loop suitable single-line trace species outputs are combined, i.e., ${ }^{12} \mathrm{CO}_{2}$ and ${ }^{13} \mathrm{CO}_{2}$, as well as $\mathrm{H}_{2} \mathrm{O}(X)$ with $X=\{1,2,3$, 4 , which further improves the initial/background GHG profiles for $\mathrm{CO}_{2}$ and $\mathrm{H}_{2} \mathrm{O}$ for the next inner loop step.

The outer BUC loop comprises Basic-Update-Control runs and is an envelope loop over the SSR and MSR processes (details in Sect. 3.6). This loop performs two iterations of the basic GHG/isotope profiles retrieval of the first completed MSR loop. The converged retrieval results after the BUC control run are then used as final best estimate of the
GHG/isotope profiles, as schematically shown in Fig. 3. We note that the control run results in practice (in our end-to-end simulations) turn out to negligibly differ from the update run result. Thus in case of real LMIO data it likely will serve just as a quality control whether any problem with convergence has occurred at any altitude level with any GHG.

\subsection{Computation of IR refractivity, impact parameter, and altitude}

From the LIO measurements we do not get any information on the tangent point altitude of each ray as this measurement information only comprises the received IR-laser intensities in $\mathrm{dBW}$ as a function of time. Also, related to this, we have no information about the thermodynamic conditions ( $p, T$, $q$ ) affecting the LIO signal at this altitude. Therefore, since the LIO retrieval requires refractivity, impact parameter and altitude information for the IR occultation rays (cf. Fig. 2), a first algorithm step is necessary to calculate these IR parameters on the basis of the MW parameters. For this algorithm step we proceed as follows.

First, from the MW impact parameter grid as a function of time $t_{j}, a_{\mathrm{MW}}\left(t_{j}\right)$, the according MW altitude grid $z_{j}\left(t_{j}\right)$ is calculated via an iterative process (iteration index $k$ ). The starting profile of the MW altitude, $z_{j, k=0}\left(t_{j}\right)$, is derived by using the MW impact height for the purpose, i.e., we subtract the Earth's local radius of curvature $R_{\mathrm{C}}$ from the MW impact parameter, $z_{j, k=0}\left(t_{j}\right)=a_{\mathrm{MW}}\left(t_{j}\right)-R_{\mathrm{C}}\left(R_{\mathrm{C}}\right.$ is available as part of standard auxiliary output parameters from the LMO retrieval). At each iteration the MW refractive index $n_{\mathrm{MW}}\left(z_{j, k}\right)$ at any MW altitude level $z_{j, k}\left(t_{j}\right)$ is obtained by log-linear interpolation from the known MW refractive index profile. It is calculated based on the formula by Smith and Weintraub (1953) using $p, T, q$ from LMO. Bouguer's rule of the relation of impact parameters to the radial distance of rays from the curvature center (Born and Wolf, 1964) is then used to calculate an updated MW altitude $z_{j, k+1}\left(t_{j}\right)$ in the form

$z_{j, k+1}\left(t_{j}\right)=\frac{a_{\mathrm{MW}}\left(t_{j}\right)}{n_{\mathrm{MW}}\left(z_{j, k}\left(t_{j}\right)\right)}-R_{\mathrm{C}}$,

where the iteration is accepted converged and stopped when the change of the MW altitude per iteration step, $\left|z_{j, k+1}\left(t_{j}\right)-z_{j, k}\left(t_{j}\right)\right|$, becomes $<0.1 \mathrm{~m}$. The iteration algorithm is robust and fast and convergence is reached within a single or very few iterations.

The IR refractivity, impact parameter, and altitude computation now can use this MW altitude level as a function of time $z_{j}\left(t_{j}\right)$ in a form strictly consistent with the retrieved MW impact parameters and $p, T, q$ from LMO. Note that in principle one might use the retrieved MW altitude from LMO directly. Dependent on algorithmic implementation of LMO retrieval this may not be directly related to the time grid of the occultation rays, however, while the impact parameters are formally related based on geometric-optical formulation 
of ray paths. Furthermore, the LIO computations will base the IR refractivity computation on $p, T, q$, so that the same way of using the information is advisable also for MW refractivity. This will ensure strict consistency of final differences of MW and IR altitudes despite the small extra errors that have been incurred when retrieving $p, T, q$ from MW refractivity. Therefore a preparation of $z_{j}\left(t_{j}\right)$ as introduced here is better than a direct use of MW altitudes, even if the latter are kept related to the original time grid in the LMO retrieval (as we currently also do in the EGOPS LMO retrieval; Schweitzer et al., 2011b). In principle also a different altitude grid than the MW grid used here could be employed as starting point but this one was found clearly most suitable for a reliable and fast subsequent derivation of the IR impact parameter and altitude grid.

Since we use the index $j$ for the MW altitude at times $t_{j}$, and later the index $i$ for the IR level at the same times $t_{i}=t_{j}$, the MW altitude notation is used in the simplified form $z_{j}$ hereafter. We can now compute the IR refractivity, impact parameter, and bending angle at the $z_{j}$ grid. We formulate the IR refractivity (in N-units) based on Bönsch and Potulski (1998) as

$N\left(z_{j}\right)=\left(c_{1}+\frac{c_{2}}{d_{1}-\frac{1}{\lambda^{2}}}+\frac{c_{3}}{d_{2}-\frac{1}{\lambda^{2}}}\right) \frac{p\left(z_{j}\right)}{T\left(z_{j}\right)}-\varepsilon_{1} e\left(z_{j}\right)$,

where the constants are $c_{1}=23.7104 \mathrm{~K} \mathrm{hPa}^{-1}, c_{2}=6839.34$ $\mathrm{K} \mathrm{hPa}^{-1}, c_{3}=45.473 \mathrm{~K} \mathrm{hPa}^{-1}, d_{1}=130.0, d_{2}=38.9$, and $\varepsilon_{1}=0.038 \mathrm{hPa}^{-1} . \quad \lambda$ is the wavelength of the IR-laser signals in units $\mu \mathrm{m}$, for our LIO signals in the range of $2 \mu \mathrm{m}$ to $2.5 \mu \mathrm{m}, p$ the pressure in $\mathrm{hPa}, T$ the temperature in $\mathrm{K}$, and $e$ the water vapor partial pressure in $\mathrm{hPa}$. This refractivity expression at the $z_{j}$ grid is computed after first interpolating $p$, $T, q$ from their native LMO grid to the $z_{j}$ grid. Equation (2) is a streamlined single-equation form of the more sophisticated empirical formulation of Bönsch and Potulski (1998). It follows very closely the Bönsch and Potulski (1998) formulation (at $\lambda>0.5 \mu \mathrm{m}$ ) and can be considered an improved version of the classical very similar optical refractivity formula developed by Edlén (1966). Different from the SmithWeintraub formula of microwave refractivity used in LMO (Schweitzer et al., 2011b), the water vapor term in this optical refractivity formula is essentially negligible because the frequencies are much too high for the permanent dipole moments of the water vapor molecules to contribute an orientation polarization term (the "wet term" in the microwave formula; e.g., Kursinski et al., 1997). The difference of the MW refractivity and the IR refractivity is illustrated over the range $2 \mu \mathrm{m}$ to $3 \mu \mathrm{m}$ by Schweitzer et al. (2011a). Based on $N\left(z_{j}\right)$, the IR refractive index $n_{j}$ (dimensionless) is

$n_{j}=n\left(z_{j}\right)=1+10^{-6} N\left(z_{j}\right)$,

which is used in the further calculations.
The IR impact parameter $a_{j}$ is subsequently, again using Bouguer's rule (Born and Wolf, 1964), computed as

$a_{j}=a\left(z_{j}\right)=n\left(z_{j}\right) r\left(z_{j}\right)=n\left(z_{j}\right)\left(z_{j}+R_{\mathrm{C}}\right)$,

where $r\left(z_{j}\right)=r_{j}=z_{j}+R_{\mathrm{C}}$ is the radial distance from the Earth's curvature center at the mean tangent point location of the occultation event.

Based on the $n_{j}, r_{j}$, and $a_{j}$ profiles, the IR bending angle profile $\alpha\left(a_{j}\right)$ corresponding to the $z_{j}$ grid is then computed as

$\alpha\left(a_{j}\right)=2 a\left(z_{j}\right) \int_{r\left(z_{j}\right)}^{r_{\text {top }}} \frac{1}{\sqrt{n^{2}(z) r^{2}(z)-a^{2}\left(z_{j}\right)}} \frac{\mathrm{d} \ln (n(z))}{\mathrm{d} r} \mathrm{~d} r$,

which is the classical Abel transform for converting refractive index to bending angle (Fjeldbo and Eshleman, 1965; Fjeldbo et al., 1971). For computing it, we employ a standard numerical implementation of this Abel integral in EGOPS (setting $r_{\text {top }}$ to $80 \mathrm{~km}$, leaving negligible residual error at the altitudes of interest up to $40 \mathrm{~km}$; Steiner et al., 1999).

With the IR refractive index, impact parameter, and bending angle profiles available at the MW altitude grid $z_{j}\left(t_{j}\right)$, we can now compute the impact parameter grid of the IR occultation rays, $a_{i}\left(t_{i}=t_{j}\right)$. We do this by exploiting the unique geometrical relation which the bending angle and impact parameter have to fulfill for representing a valid occultation ray at any joint LIO and LMO measurement time $t_{i}=t_{j}$ between the corresponding joint LIO and LMO transmitter and receiver positions, $r_{\mathrm{Tx}, i}=r_{\mathrm{Tx}, j}$ and $r_{\mathrm{Rx}, i}=r_{\mathrm{Rx}, j}$. This geometrical relation reads (Melbourne et al., 1994; Syndergaard, 1999; Kirchengast et al., 2006)

$\alpha_{\mathrm{g}}\left(a_{i}\right)=\theta_{i}-\arccos \left(\frac{a\left(z_{i}\right)}{r_{\mathrm{Tx}, i}}\right)-\arccos \left(\frac{a\left(z_{i}\right)}{r_{\mathrm{Rx}, i}}\right)$,

where $\alpha_{\mathrm{g}}\left(a_{i}\right)$ and $a\left(z_{i}\right)$ denote the desired point on the (interpolated) IR bending angle profile $\alpha\left(a_{j}\right)$ (Eq. 5) that represents the IR occultation ray. The angle $\theta_{i}$ is the opening angle between the transmitter and the receiver at time $t_{i}$ (see Fig. 1). Since this is no explicit formulation, we must find the desired point iteratively for which we also use the (analytically available) derivative of Eq. (6), $\alpha_{\mathrm{g}}^{\prime}\left(a_{i}\right)$, which reads

$\alpha_{\mathrm{g}}^{\prime}\left(a_{i}\right)=\frac{\mathrm{d} \alpha_{\mathrm{g}}}{\mathrm{d} a}\left(a_{i}\right)=\frac{1}{r_{\mathrm{TX}, i} \sqrt{1-\left(\frac{a\left(z_{i}\right)}{r_{\mathrm{T}, i}}\right)^{2}}}+\frac{1}{r_{\mathrm{Rx}, i} \sqrt{1-\left(\frac{a\left(z_{i}\right)}{r_{\mathrm{R}, i}}\right)^{2}}}$.

We use an implementation of Newton's method for the iteration process (iteration index $k$ ), searching for the desired impact parameter $a_{i}$ by updating the bending angle difference of $\alpha_{\mathrm{g}}\left(a_{i}\right)$ (Eq. 6) and $\alpha\left(a_{i}\right)$ (interpolated from Eq. 5), and the subsequently estimated impact parameter difference, until convergence is achieved. In this process according to the update rules given below, $\alpha\left(a_{i}\right)$ is log-linearly interpolated from the profile $\alpha\left(a_{j}\right)$ and the derivative $\alpha_{\mathrm{g}}^{\prime}\left(a_{i}\right)$ supports the impact parameter difference estimate and provides 
the direction of the iterative difference minimization process. As initial value for any time $t_{i}=t_{j}$ we use the MW impact parameter, $a_{k=0}=a\left(z_{i}\right)=a_{j}$, which is a good initial guess since the IR and MW ray path differences $a_{i}-a_{j}$ and $z_{i}-z_{j}$ are small. The update rules for the iteration are given by

$$
\begin{aligned}
& \Delta \alpha_{k+1}=\alpha_{\mathrm{g}}\left(a_{k}\right)-\alpha\left(a_{k}\right) \\
& \Delta a_{k+1}=\frac{1}{\eta\left(z_{j}\right)} \frac{\Delta \alpha_{k+1}}{\alpha_{\mathrm{g}}^{\prime}\left(a_{k}\right)} \\
& a_{k+1}=a_{k}-\Delta a_{k+1} .
\end{aligned}
$$

In Eq. (9), the altitude-dependent relaxation factor $\eta\left(z_{j}\right)$ ensures robust convergence despite the iteration problem is one-sided convergent for the larger MW and IR ray separations into the troposphere (un-relaxed iteration can lead to convergence to a spurious oscillating bi-stable solution, beyond the first bifurcation in the state space of the given iteration problem). We formulated $\eta\left(z_{j}\right)$ as

$\eta\left(z_{j}\right)=\eta_{\text {top }}\left(1+\frac{3}{2} \exp \left[-\frac{\left(z_{j}-z_{\text {base }}\right)}{H_{\text {atm }}}\right]\right)$,

where the minimum relaxation factor at high altitudes $\eta_{\text {top }}$ is set to 2 , the base altitude $z_{\text {base }}$ to $5 \mathrm{~km}$ and the atmospheric scale height $H_{\text {atm }}$ to $7 \mathrm{~km}$. This provides robust and at the same time still fast convergence within a few iterations. The iteration is accepted converged and stopped when the change of the IR impact parameter per iteration step, $\left|\Delta a_{k+1}\right|$, becomes $<0.1 \mathrm{~m}$. Based on GRO and LMO experience with bending angle and impact parameter retrieval, an additional criterion back-checks the impact parameter solution for vertical monotony (i.e., next downward ray needs to always have an impact parameter lower than the previous ray). The processing is terminated at the altitude level where the monotony is first violated if that occurs before the bottom of the $z_{j}$ grid. This safeguards from potential errors in the LMO-retrieved input data at lowest tropospheric altitude levels.

The final converged values $a_{k+1}$ at all measurement times $t_{i}=t_{j}$ of the occultation event provide the resulting $a_{i}$ levels of IR impact altitudes. We can now log-linearly interpolate the IR refractive index from the $a_{j}$ grid corresponding to the $z_{j}$ grid (Eqs. 3 and 4) to this $a_{i}$ grid, yielding the resulting IR refractive index profile $n\left(a_{i}\right)$. Using Bouguer's rule again (as in Eq. 1), we finally also obtain the resulting $z_{i}$ grid of IR altitudes. All subsequent LIO retrieval steps can thus now use together with the $t_{i}$ grid also its associated $a_{i}$ or $z_{i}$ grids.

\subsection{Single-line trace species retrieval (SSR)}

The SSR algorithm is the core of the LIO trace species retrieval. In this step, one absorption-reference channel pair of measured LIO intensities is used to derive one trace species profile (cf. Figs. 2 and 3, red boxes). The detailed steps are explained in the following sections, accompanied by illustration of the steps. Example results are illustrated for the trace species ${ }^{12} \mathrm{CO}_{2}$ (Fig. 4) and $\mathrm{H}_{2} \mathrm{O}$ (2) (Fig. 5); for a full list of single-line trace species see Table 1 (for details on the related LMIO mission design see Kirchengast et al., 2010a; Schweitzer, 2010; Kirchengast and Schweitzer, 2011).

\subsubsection{Defocusing correction}

The starting point are the raw, quasi-realistically simulated LIO signal power profiles in $\mathrm{dBW}$ reaching the receiver detectors, as shown in Figs. 4a and 5a. These panels show the signal power profiles as a function of time for the absorption channel (solid green line) and for the reference channel (dashed-dotted red line). The atmospheric settings are defined in Sect. 2.2. In practice, power normalized to a reference power value, $\tilde{P}$ in $\mathrm{WW}^{-1}$, is then used. For real data the reference generally is the noise-equivalent power of the detection system (Schweitzer et al., 2011a), leading to the signal-to-noise ratio, and for simulated data in EGOPS we use the power value at the top-altitude level. From the previous preparatory step (cf. Sect. 3.3) we can allocate to every power value $\tilde{P}\left(t_{i}\right)$ an IR impact parameter $a_{i}$ and IR altitude $z_{i}$, respectively.

The defocusing correction clears the signal powers from the influence of spherical signal spreading and differential bending, which reduces the signal power increasingly from top to bottom by up to a maximum defocusing loss of near $5 \mathrm{~dB}$ at $5 \mathrm{~km}$ (cf. Schweitzer et al., 2011a). The "bump" on the power profiles visible within $5 \mathrm{~s}$ to $7 \mathrm{~s}$ in Figs. $4 \mathrm{a}$ and $5 \mathrm{a}$ is a feature of the defocusing around the tropopause height, due to the sharp change of the vertical gradient of the refractive index there. The defocusing correction is based on equations developed by Jensen et al. (2003). A detailed algorithmic description of the defocusing correction for LMO, which we identically use in the LIO retrieval, is given by Schweitzer et al. (2011b) who also address its limitations in non-spherically symmetric atmospheres; residual effects of horizontal gradients only cancel in differential transmissions between neighbor frequencies as formed in Sect. 3.4.2 below. As top-of-atmosphere (TOA) reference power, needed in the algorithm, we use the measured LIO signal powers at an altitude of $65 \mathrm{~km}$ with an averaging interval of $4 \mathrm{~km}$. At these high altitude levels negligible absorption takes place at the channel frequencies selected so that we have essentially unity transmission and otherwise only noise contributions. In the LMO retrieval (Schweitzer et al., 2011b), the defocusing loss is applied to amplitudes but it is equally valid for powers (with dB-conversion factor of 10 instead of 20). For LIO the corrected power profiles in $\mathrm{dB}$, applying a defocusing correction term $\left(\tilde{P}_{\mathrm{dc}}\left(a_{i}\right)\right)$ analogously to Schweitzer et al. (2011b), are given by

$\mathcal{T}\left(a_{i}\right)=-10\left[\log \left(\tilde{P}\left(a_{i}\right)\right)-\log \left(\tilde{P}_{\mathrm{dc}}\left(a_{i}\right)\right)\right]$.

The resulting transmission profiles for absorption and reference channel after the defocusing correction are illustrated in Figs. $4 \mathrm{~b}$ and $5 \mathrm{~b}$. We note that the defocusing correction 

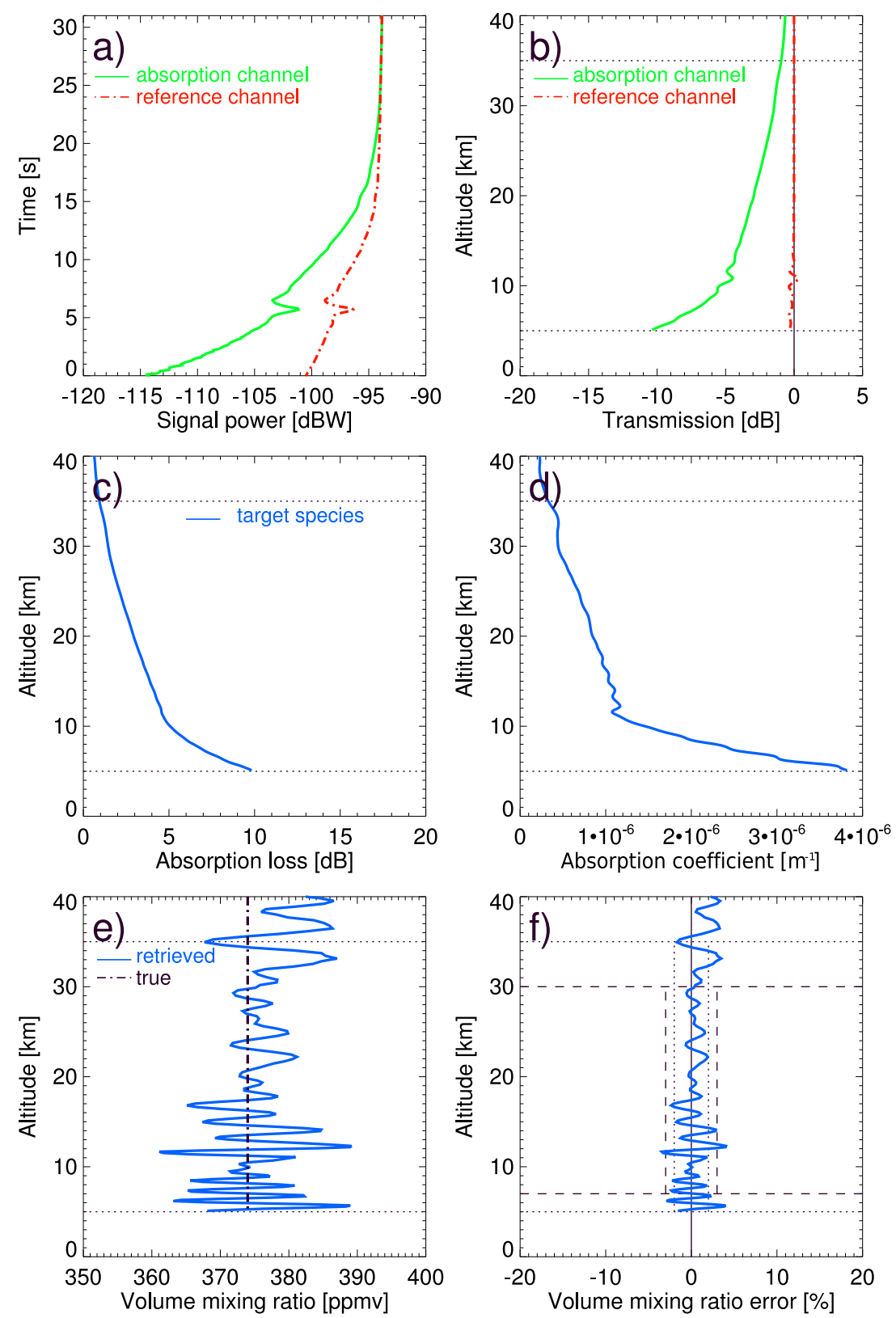

Fig. 4. Illustration of the single-line trace species retrieval (SSR) algorithm for the single-line species ${ }^{12} \mathrm{CO}_{2}$. (a) LIO input profiles, simulated signal powers for the ${ }^{12} \mathrm{CO}_{2}$ absorption (green solid line) and reference (red dashed-dotted line) channel as a function of time. (b) Transmission profiles for the two channels after defocusing and spreading correction and allocation to the IR altitude grid. (c) ${ }^{12} \mathrm{CO}_{2}$ absorption loss profile after absorption-reference channel differencing and correction for all background effects. (d) ${ }^{12} \mathrm{CO}_{2}$ absorption coefficient profile after Abel transform retrieval. (e) Retrieved (blue solid) and true (black dashed-dotted) ${ }^{12} \mathrm{CO}_{2}$ volume mixing ratio (VMR) profile. (f) ${ }^{12} \mathrm{CO}_{2}$ VMR retrieval error profile (retrieved-minus-true relative to true). The horizontal and vertical dotted/dashed lines - especially used in panel (f) - indicate the target/threshold observational requirements for altitude domain and accuracy for the LMIO mission concept (Larsen et al., 2009; Kirchengast et al., 2010a).

is not necessarily needed if differential transmission is used, such as we will use here for the GHG profiling. This applies because the very closely spaced LIO absorption and reference channel frequencies experience the same defocusing and beam spreading, which is thus automatically corrected for simply by the use of differential transmissions. However, differential transmissions can generally not be used when targeting information such as aerosol extinction, scintillation strength, or cloud layering profiles. These require the use of single-channel transmissions directly and in those cases the defocusing correction will thus be needed. 

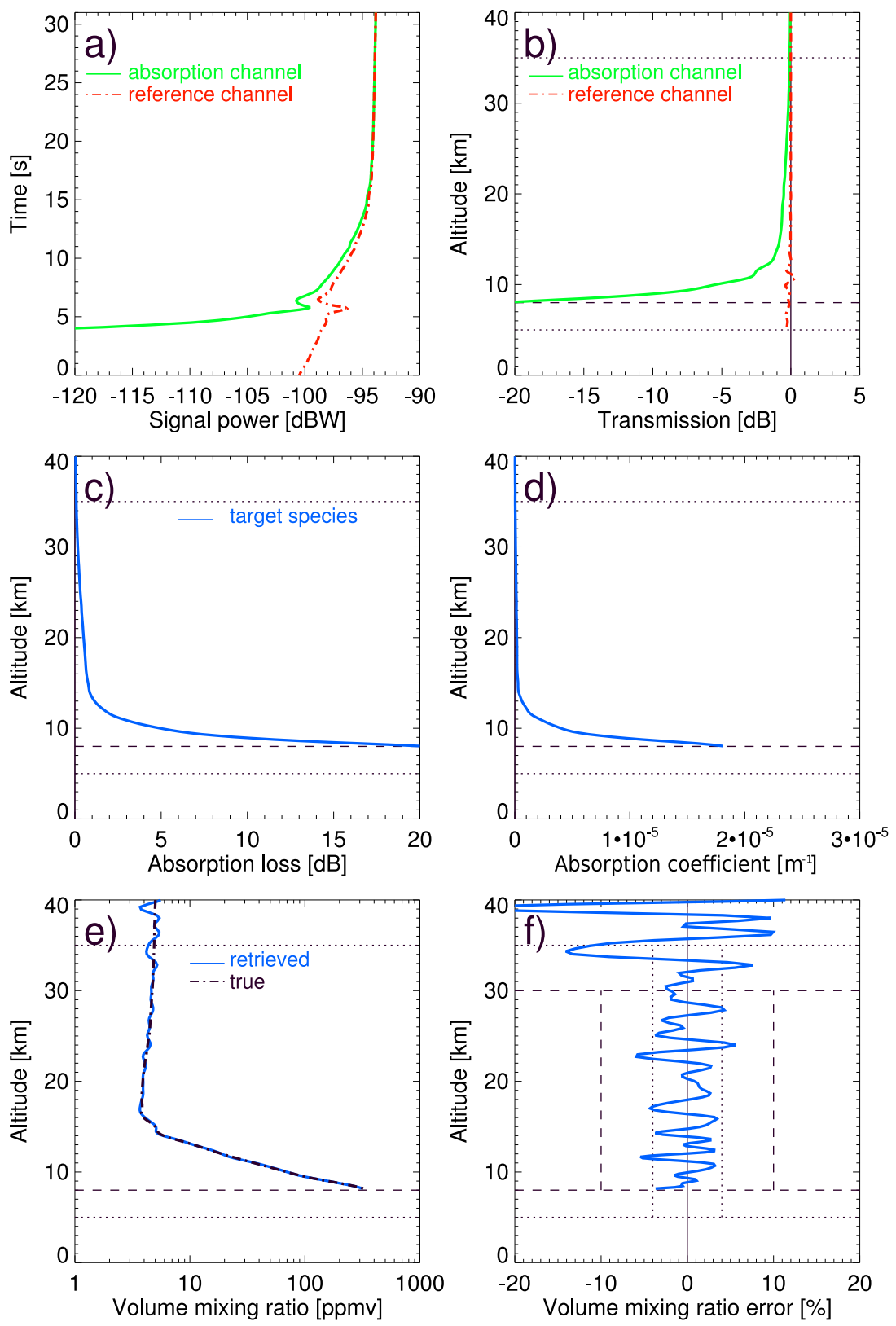

Fig. 5. Illustration of the single-line trace species retrieval (SSR) algorithm for the single-line species $\mathrm{H}_{2} \mathrm{O}(2)$. The layout is the same as in Fig. 4; see that caption for explanation.

\subsubsection{Target species transmission retrieval}

The starting point for the target species transmission retrieval are the transmissions of a channel pair consisting of an absorption and a reference channel (either raw transmissions or defocusing-corrected transmission as explained in Sect. 3.4.1). Such transmissions can be seen in Fig. $4 \mathrm{~b}$ for the retrieval of ${ }^{12} \mathrm{CO}_{2}$ and in Fig. $5 \mathrm{~b}$ for the retrieval of $\mathrm{H}_{2} \mathrm{O}(2)$, respectively. In this section we discuss how these transmission profiles are corrected from further atmospheric influences, such as scintillation noise, aerosol extinction,
Rayleigh scattering and absorption due to foreign species. The output will be the pure transmission profile due to the target species only.

\section{Correction for broadband atmospheric effects}

Since the transmissions of the absorption-channel signal $\mathcal{T}_{\text {Abs }}\left(a_{i}\right)$ and the reference-channel signal $\mathcal{T}_{\text {Ref }}\left(a_{i}\right)$, both given in $\mathrm{dB}$, experience very similar broadband atmospheric influences (in air without clouds especially scintillation, aerosol extinction, broadband/continuum absorption, and 
Rayleigh scattering; cf. Schweitzer et al., 2011a; Schweitzer, 2010), a simple difference of the two channel transmission profiles eliminates these influences to a high degree

$\Delta \mathcal{T}\left(z_{i}\right)=\Delta \mathcal{T}\left(a_{i}\right)=\mathcal{T}_{\text {Abs }}\left(a_{i}\right)-\mathcal{T}_{\operatorname{Ref}}\left(a_{i}\right)$.

This differential transmission profile $\Delta \mathcal{T}\left(z_{i}\right)$ in $\mathrm{dB}$ at the $z_{i}$ grid (applicable interchangeably with the $a_{i}$ grid) is corrected for potentially remaining absorption effects from absorption lines of foreign species that are not broad and overlap the target species absorption line.

\section{Correction for foreign species absorption}

As the absorption and/or reference signal have, despite a careful channel selection process (Kirchengast and Schweitzer, 2011), some small but non-negligible sensitivity to line absorption by foreign species (Schweitzer, 2010; Schweitzer et al., 2011a), these residual foreign species absorptions need to be eliminated as well. Their influence is modeled by use of the initial/background GHG trace species profiles. Specifically, the absorption channel needs to be corrected for the absorption of all foreign species, the reference channel for the absorption of all foreign species plus the target species (the latter being in the reference channel, where absorption ideally should be truely zero, also a type of foreign species; therefore we use here the simplified generic terminology "foreign species correction"). The set of foreign species accounted for is composed of the potentially relevant foreign species $\{M: X \backslash\{$ Target : Target $\in X\}\}$ where $X=\left\{\mathrm{N}_{2} \mathrm{O}, \mathrm{CH}_{4},{ }^{12} \mathrm{CO}_{2},{ }^{13} \mathrm{CO}_{2}, \mathrm{C}^{18} \mathrm{OO}, \mathrm{H}_{2} \mathrm{O}, \mathrm{HDO}, \mathrm{H}_{2}^{18} \mathrm{O}\right.$, $\mathrm{CO}, \mathrm{O}_{3}$; ; all others are negligible at the selected LIO channel frequencies.

The transmissions for the foreign species were calculated in the xEGOPS system with the Reference Forward Model (RFM) (Edwards, 1996; Dudhia, 2008), using the spectroscopic parameters from HITRAN2004 (Rothman et al., 2005) and user-supplied atmospheric profiles (see RFM introduction in Sect. 2.2). Here we supply RFM with the LMO profiles $p, T$ and the initial/background GHG profiles to obtain the ensemble of modeled species transmissions needed (see Fig. 2). For the absorption channel we use the ensemble $\{M\}$ for computing the background transmission $\mathcal{T}_{\text {Abs, bgr }}\left(z_{i}\right)$ from the foreign species, for the reference channel we use the ensemble of all species $\{X\}$ to compute the background transmission $\mathcal{T}_{\text {Ref,bgr }}\left(z_{i}\right)$. The difference of these two modeled background transmission profiles yields the differential background transmission profile from the foreign species, $\Delta \mathcal{T}_{\text {bgr }}\left(z_{i}\right)$, given by

$\Delta \mathcal{T}_{\text {bgr }}\left(z_{i}\right)=\mathcal{T}_{\text {Abs,bgr }}\left(z_{i}\right)-\mathcal{T}_{\text {Ref, bgr }}\left(z_{i}\right)$.

The pure target species transmission in the absorption channel, $\mathcal{T}_{\text {tgt }}\left(z_{i}\right)$, can thus be obtained by subtracting the differential background transmission profile $\Delta \mathcal{T}_{\text {bgr }}\left(z_{i}\right)$ (Eq. 14) from the differential transmission profile $\Delta \mathcal{T}\left(z_{i}\right)$ (Eq. 13),
$\mathcal{T}_{\text {tgt }}\left(a_{i}\right)=\mathcal{T}_{\text {tgt }}\left(z_{i}\right)=\Delta \mathcal{T}\left(z_{i}\right)-\Delta \mathcal{T}_{\text {bgr }}\left(z_{i}\right)$,

where the resulting target species transmission profile (in units $\mathrm{dB}$ ) can again be alternatively used at the $a_{i}$ grid, which is needed for the next step of absorption coefficient retrieval.

The magnitude of $\mathcal{T}_{\text {tgt }}\left(z_{i}\right)$, the target species absorption loss profile, is illustrated for the ${ }^{12} \mathrm{CO}_{2}$ and $\mathrm{H}_{2} \mathrm{O}(2)$ channels in Figs. $4 c$ and $5 c$, respectively. The $\mathrm{H}_{2} \mathrm{O}(2)$ absorption loss exceeds the upper bound of favorable dynamic range $\left(0.25 \mathrm{~dB}<\left|\mathcal{T}_{\text {tgt }}\left(z_{i}\right)\right|<13 \mathrm{~dB}\right.$, corresponding to about $5 \%$ to $95 \%$ absorption; Kirchengast and Schweitzer, 2011; Schweitzer et al., 2011a) at altitudes below about $8.5 \mathrm{~km}$. This indicates why for $\mathrm{H}_{2} \mathrm{O}$, with its very high dynamic range of concentrations over the UTLS, several single-line species are needed to properly cover the full UTLS. The absorption loss for ${ }^{12} \mathrm{CO}_{2}$ is within the favorable dynamic range from top to bottom over the UTLS, reaching about $10 \mathrm{~dB}$ at an altitude of $5 \mathrm{~km}$. Typical sizes of the target species and foreign species transmissions of all other GHG species according to Table 1 are found in Schweitzer et al. (2011a) for a set of representative atmospheric conditions.

\subsubsection{Absorption coefficient retrieval}

The next important step is the retrieval of the (volume) absorption coefficient $\kappa\left(z_{i}\right)$ in units $\mathrm{m}^{-1}$ from the target species transmission profile $\mathcal{T}_{\text {tgt }}\left(a_{i}\right)$. For this purpose we employ the same absorptive Abel transform as used and described in detail by Schweitzer et al. (2011b) for the LMO absorption coefficient retrieval. This type of Abel transform leads to noise amplification by about a factor of 2 to 2.5 (Sofieva and Kyrölä, 2004). The absorptive Abel transform implementation in EGOPS is very robust, however, and designed to minimize this noise amplification (Schweitzer et al., 2011b).

The resulting example absorption coefficient profiles for ${ }^{12} \mathrm{CO}_{2}$ and $\mathrm{H}_{2} \mathrm{O}(2)$ are shown in Figs. $4 \mathrm{~d}$ and $5 \mathrm{~d}$, respectively. It is seen, best visible for the ${ }^{12} \mathrm{CO}_{2}$ case, that the noise increases from the absorption loss profile to the absorption coefficient profile due to the noise amplification discussed above. Future more special filtering may slightly reduce this noise further; regarding resolution the filtering is currently set to yield a high vertical resolution of about $1 \mathrm{~km}$ (Schweitzer et al., 2011b). In terms of absorption coefficient magnitudes, profiles are useful for subsequent atmosperic profiles retrieval with high accuracy ( $1 \%$ level) within an absorption coefficient range of about $10^{-7} \mathrm{~m}^{-1}$ to $10^{-5} \mathrm{~m}^{-1}$ as also discussed by Schweitzer et al. (2011b). Consistent with the respective behavior of the absorption loss profile, the ${ }^{12} \mathrm{CO}_{2}$ absorption coefficient profile fully fits this range while the $\mathrm{H}_{2} \mathrm{O}(2)$ one begins to exceed it near $8 \mathrm{~km}$ and other $\mathrm{H}_{2} \mathrm{O}$ channels will have to complement it in the lowest part of the UTLS towards $5 \mathrm{~km}$. 


\subsubsection{Atmospheric profiles retrieval}

The last step of the SSR process is the retrieval of atmospheric profiles, in particular of the volume mixing ratio (VMR) profile of the GHG or minor isotope target species, $\chi\left(z_{i}\right)$ in units ppmv, from the absorption coefficient profile $\kappa\left(z_{i}\right)$ in units $\mathrm{m}^{-1}$. In addition (see Fig. 2) we need a modeled molar absorption cross section of the target species $\epsilon\left(z_{i}\right)$ (units $\mathrm{m}^{2} \mathrm{~mol}^{-1}$ ). This is computed again with RFM, based on the initial/background target species profile (units ppmv) and the $p$ (units $\mathrm{Pa}$ ) and $T$ (units $\mathrm{K}$ ) profiles from LMO interpolated to the $z_{i}$ grid.

With these input profiles, the VMR profile $\chi\left(z_{i}\right)$ is then calculated as

$$
\chi\left(z_{i}\right)=10^{6} R^{*} \frac{\kappa\left(z_{i}\right)}{\epsilon\left(z_{i}\right)} \frac{T\left(z_{i}\right)}{p\left(z_{i}\right)},
$$

where $R^{*}=8.3145 \mathrm{~J} /(\mathrm{K} \mathrm{mol})$ is the universal molar gas constant and the factor $10^{6}$ is the conversion factor from dimensionless fraction to ppmv (e.g., Salby, 1996). We note that alternatively or additionally we also could compute the target species dry air mole fraction and/or the target species absolute concentration, likely preferable for some applications in case of real data. In this end-to-end simulation framework we can refrain from computing these additional profiles, however, since the VMR profile is well representative and convertible with the help of the thermodynamic profiles to any other representation.

The resulting example VMR profiles for ${ }^{12} \mathrm{CO}_{2}$ and $\mathrm{H}_{2} \mathrm{O}(2)$ are shown in Figs. 4e and 5e, and the relative VMR error is displayed in Figs. $4 \mathrm{f}$ and $5 \mathrm{f}$, respectively. It can be seen that ${ }^{12} \mathrm{CO}_{2}$ is retrieved to higher accuracy than $\mathrm{H}_{2} \mathrm{O}$. The relative error of $\mathrm{CO}_{2}$, looked at as a standard deviation, is within $2 \%$ over the ULTS due to the good absorption signal at all altitudes (Fig. $4 \mathrm{c}$ and d). The $\mathrm{H}_{2} \mathrm{O}(2)$ is more at a standard deviation near $3 \%$, and beyond above about $32 \mathrm{~km}$, since the absorption signal (Fig. 5c and d) is less favorably distributed over the UTLS.

Generally these single-line example retrievals appear unbiased and at fairly high accuracy, within the target observational requirements (marked on the panels) that were set by scientific objectives of atmosphere and climate research planned to be supported by LMIO data (Larsen et al., 2009; Kirchengast et al., 2010a). More details on the performance are discussed in the sections below.

\subsection{Multi-line trace species retrieval (MSR)}

This section discusses the inner loop of the LIO retrieval, called multi-line trace species retrieval (MSR) (cf. Fig. 3). This MSR loop handles the consecutive retrieval of the multiple species. Its purpose is to ensure that the set of trace species is retrieved in a well defined order and to update the set of the initial/background GHG profiles so that the SSR core process finds this set improved by a new retrieved profile after every step of the MSR loop (details in Sect. 3.5.1).
The set is needed in the SSR for the foreign species correction (Sect. 3.4.2) within the target species transmission retrieval and for the molar absorption cross section calculation (Sect. 3.4.4) within the atmospheric VMR profile retrieval. Additionally, the composite VMR profiles of $\mathrm{CO}_{2}$ and $\mathrm{H}_{2} \mathrm{O}$ are improved at each step of the MSR loop by combining adequate retrieved single-line species profiles (details in Sect. 3.5.2).

\subsubsection{Trace species retrieval order}

Generally, the SSR process requires the VMR profiles of the main atmospheric absorbers to be able to compute the contribution of foreign species absorption to the transmission of the absorption and reference channels (as explained in Sect. 3.4.2). At the very start of the MSR process (at the start of the basic run of the outer loop), the array of retrieved trace species profiles of the relevant atmospheric absorbers (which are $\mathrm{H}_{2} \mathrm{O}, \mathrm{CO}_{2}, \mathrm{CH}_{4}, \mathrm{~N}_{2} \mathrm{O}, \mathrm{O}_{3}, \mathrm{CO}$ for our channels) is set to initial values, which might be a priori VMR profiles from an atmospheric model or even just zero. In the LIO retrieval these initial/background GHG profiles (cf. LIO auxiliary input in Fig. 2) are either taken from a FASCODE atmosphere that is somewhat adjacent in atmospheric conditions to the FASCODE atmosphere used as "true" one in the forward modeling (e.g., standard atmosphere as initial if tropical is the "true"), or set to zero for test purposes.

After the first SSR step, one obtains the VMR profile of the target species (see Sect. 3.4.4) that is first in the order. The respective initial/background GHG profile is then updated by this retrieved one. All other species remain at the initial values. In this spirit the MSR proceeds to perform a full chain of SSRs, consecutively retrieving the target species in a sensible order, and after each SSR step the set of initial/background GHG profiles gets improved by a new retrieved profile. Hence, the foreign species correction for the absorption and reference channel in the SSR (cf. Sect. 3.4.2) gets improved every step as more and more initial profiles are superseded by actual retrieved profiles. Thus overall the MSR is an envelope process over the SSR, which after a complete first MSR loop (complete basic run) has entirely superseded the original set of initial/background GHG profiles by retrieved profiles. Even if the intial values were zero, this first full set of retrieved profiles can be expected to be very accurate already since the foreign species interference is very small thanks to the careful selection of the LIO channels (Kirchengast and Schweitzer, 2011; Schweitzer et al., 2011a).

To ensure such accurate retrieval results, it is key to employ a well defined sequence in which the VMR profiles of the single gases are retrieved by the SSR process. Since the channels used for retrieving the species have different sensitivity to foreign species absorption, those gases need to be retrieved first the channels of which exhibit least sensitivity to any other species. In the case of the set of channels 

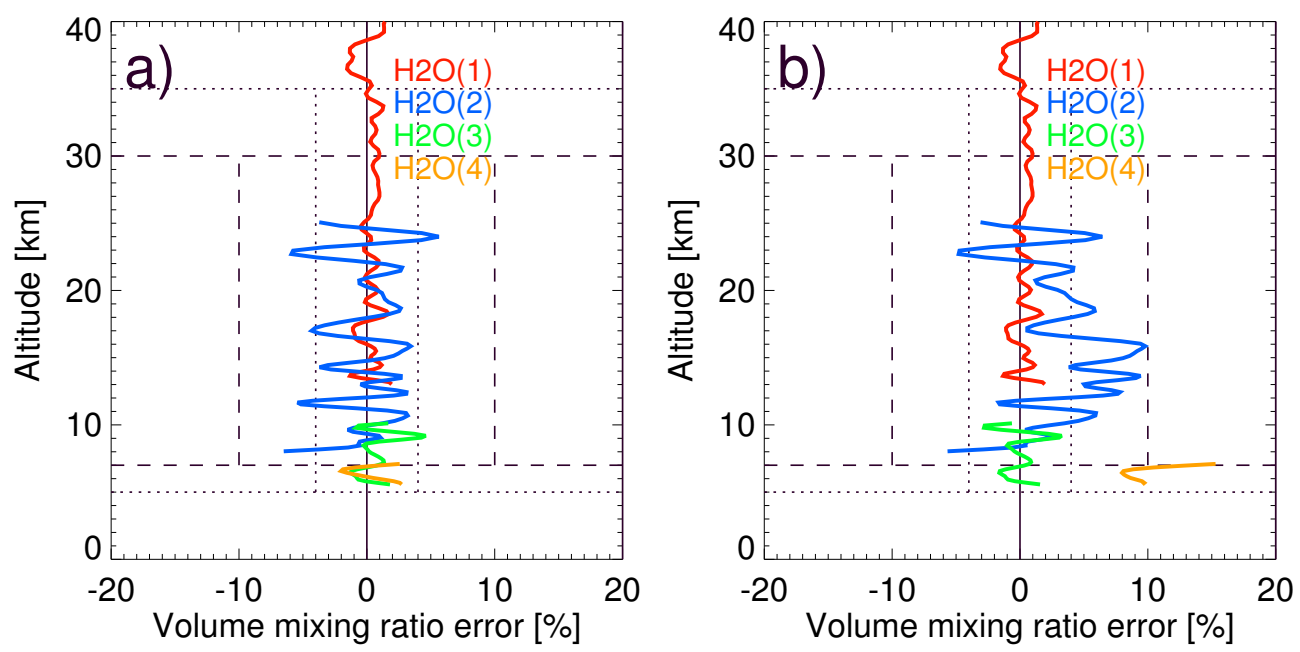

Fig. 6. Demonstration of the influence of the single-line trace species order in the MSR loop on VMR retrieval errors of the four single-line species $\mathrm{H}_{2} \mathrm{O}(X)(X=\{1,2,3,4\})$. VMR errors from a correct and sensible order (a) are shown compared to VMR errors for an intentionally sub-optimal order, where no $\mathrm{CO}_{2}$ retrieval was placed before the $\mathrm{H}_{2} \mathrm{O}$ retrievals (b); see the text in Sect. 3.5.1 for further explanation.

used in this study, a very suitable sequence that we found based on the studies of atmospheric influences on LIO signals by Schweitzer (2010) and Schweitzer et al. (2011a) is listed in Table 1. That is, in Table 1 the sensitivity to foreign species absorption is generally lowest to highest from top to bottom and at the same time the foreign influence on species coming later is generally highest to lowest from top to bottom. This ensures accurate retrieval results even if one starts with an initial concentration of the foreign species of zero, since the top listed ones are themselves fairly insensitive and on the other hand precede the later ones which they influence. In this way the MSR-computed set of VMR profiles is effectively independent of a priori information, enabling - together with other favorable properties from using the occultation principle with coherent signals - its climate benchmarking capability (Kirchengast et al., 2010a; Kirchengast and Schweitzer, 2011).

An illustrative example result of the dependency of the retrieval on the species order in the set of initial/background GHG profiles is given in Fig. 6. In these panels VMR errors are shown for the $\mathrm{H}_{2} \mathrm{O}(X)$ single-line retrievals with $X=\{1$, $2,3,4\}$. The individual $\mathrm{H}_{2} \mathrm{O}(X)$ channels are suitable for different altitudes as indicated in Table 1. Figure 6a shows the SSR error results for the four $\mathrm{H}_{2} \mathrm{O}(X)$ cases when using the correct initial/background GHG profile order according to Table $1\left(\mathrm{~N}_{2} \mathrm{O}, \mathrm{CH}_{4}, \mathrm{CO}_{2}\right.$, etc.). In contrast, Fig. 6b shows the VMR error profiles for the four $\mathrm{H}_{2} \mathrm{O}(X)$ cases when using a zero-valued initial/background $\mathrm{CO}_{2}$ profile, i.e., when not retrieving $\mathrm{CO}_{2}$ before $\mathrm{H}_{2} \mathrm{O}$. The concentrations of $\mathrm{N}_{2} \mathrm{O}$ and $\mathrm{CH}_{4}$ were set to the correct values. It can be seen that the $\mathrm{H}_{2} \mathrm{O}(2)$ and $\mathrm{H}_{2} \mathrm{O}(4)$ channels show a significant dependence on the $\mathrm{CO}_{2}$ VMR profile (while the $\mathrm{H}_{2} \mathrm{O}(1)$ and $\mathrm{H}_{2} \mathrm{O}(3)$ channels show nearly no dependence). Although less ambitious remote sensing systems would not care too much about errors still not higher than about $10 \%$ (that in addition would be largely part of random rather than systematic error in ensembles of profiles), these $\mathrm{H}_{2} \mathrm{O}(2)$ and $\mathrm{H}_{2} \mathrm{O}(4)$ test results are clearly at the margin of the demanding requirements for the LMIO method. It is therefore encouraging to see in Fig. 6a that a sensible order of species in the MSR does a highly effective job in keeping results unbiased and in terms of standard deviation keeping them well within target requirements already in a single basic run of the MSR loop.

\subsubsection{Composite $\mathrm{CO}_{2}$ and $\mathrm{H}_{2} \mathrm{O}$ profiles}

An important further part of the MSR process is the meaningful combination of suitable VMR profiles from the SSR in order to improve the overall VMR error of a species. This is done for ${ }^{X} \mathrm{CO}_{2}$ channels for two different isotopes and for the four $\mathrm{H}_{2} \mathrm{O}(X)$ single-line species to merge the individual profiles covering the UTLS piecewise into a composite profile covering the full UTLS.

As the general approach any composite species VMR profile $\chi_{\mathrm{c}}\left(z_{i}\right)$ is derived via summation of a number of $n$ singleline species VMR profiles $\chi_{\mathrm{m}}\left(z_{i}\right)$, scaled by their isotopic fractional abundances $a_{\mathrm{m}}$ and weighted by inverse-variances $w_{\mathrm{m}}\left(z_{i}\right)$ representing their relative uncertainty,

$\chi_{\mathrm{c}}\left(z_{i}\right)=a_{\mathrm{c}} \sum_{m=1}^{n}\left(w_{\mathrm{m}}\left(z_{i}\right) \frac{\chi_{\mathrm{m}}\left(z_{i}\right)}{a_{\mathrm{m}}}\right)$,

where the additional factor $a_{\mathrm{c}}$ is the assigned fractional abundance of the composite (usually set to unity for representing the full abundance of all isotopes of a species). Note that for the single-line species other than $\mathrm{CO}_{2}$ and $\mathrm{H}_{2} \mathrm{O}$ such as $\mathrm{CH}_{4}$ and $\mathrm{O}_{3}$ we also employ Eq. (17) in its simplest form $(n=1$, 
$a_{\mathrm{c}}=1, w_{\mathrm{m}}\left(z_{i}\right)$ is unity), just for dividing the single-species result from Eq. (16) by the respective isotopic abundance to obtain the VMR for the full species abundance. by

The inverse-variance weight $w_{\mathrm{m}}\left(z_{i}\right)$ in Eq. (17) is defined

$w_{\mathrm{m}}\left(z_{i}\right)=\frac{1}{\sum_{m=1}^{n}\left(\frac{1}{\varepsilon_{\mathrm{m}}^{2}\left(z_{i}\right)}\right)} \frac{1}{\varepsilon_{\mathrm{m}}^{2}\left(z_{i}\right)}$.

where the normalization factor of $1 / \varepsilon_{\mathrm{m}}^{2}$ ensures that the sum of all weights $w_{\mathrm{m}}$ is unity.

The isotopic fractional abundances $a_{\mathrm{m}}$ are taken from Rothman et al. (2005). The standard error profiles $\varepsilon_{\mathrm{m}}\left(z_{i}\right)$ utilized to build the variances express the altitude-dependent errors of the individual VMR profiles (in units \%), which determine the weight of any individual profile relative to the other profiles; their formulation for our specific $\mathrm{CO}_{2}$ and $\mathrm{H}_{2} \mathrm{O}$ composites is summarized below. The performance improvement derives from the fact that the error of the composite profile from the simple optimal estimation formulated by Eqs. (17) and (18) will at any altitude level always be smaller than the smallest individual profile error at that level. For example, combining two profiles with equal errors would lead to a composite profile with the error reduced by a factor of $1 / \sqrt{ } 2$. On the other hand, with two significantly unequal errors the composite profile error would be only very slightly reduced against the smaller of the two errors.

\section{$\mathrm{CO}_{2}$ composite profile and its weighting}

The composite $\mathrm{CO}_{2}$ VMR profile $\chi_{\mathrm{CO}_{2}}\left(z_{i}\right)$ is derived by combining the two isotopes ${ }^{12} \mathrm{CO}_{2}$ and ${ }^{13} \mathrm{CO}_{2}$ via inversevariance weighting including static standard errors. The rationale for combining just these two isotopes is their known highly stable isotopic ratio $\delta^{13} \mathrm{C}$ in the free atmosphere, which can thus be relied on in the combination of the profiles over the UTLS $\left(\delta^{13} \mathrm{C}\right.$ ratio variations $<0.05 \%$; Allison and Francey, 2007). Employing Eq. (17) with the composite abundance $a_{\mathrm{c}}$ set to unity, $\chi_{\mathrm{CO}_{2}}\left(z_{i}\right)$ is given by

$\chi_{\mathrm{CO}_{2}}\left(z_{i}\right)=w_{12} \mathrm{CO}_{2}\left(z_{i}\right) \frac{\chi_{12} \mathrm{CO}_{2}\left(z_{i}\right)}{a_{12} \mathrm{CO}_{2}}+w_{13} \mathrm{CO}_{2}\left(z_{i}\right) \frac{\chi_{13} \mathrm{CO}_{2}\left(z_{i}\right)}{a_{13} \mathrm{CO}_{2}}$,

where $a_{12} \mathrm{CO}_{2}=0.98420$ and $a_{13} \mathrm{CO}_{2}=0.01106$ (Rothman et al., 2005).

The needed relative VMR error profiles $\varepsilon_{\mathrm{CO}_{2}}\left(z_{i}\right)$ in $\%$ for ${ }^{12} \mathrm{CO}_{2}$ and ${ }^{13} \mathrm{CO}_{2}$ (we suppress the index $m$ for brevity in formulating $\varepsilon_{\mathrm{CO}_{2}}\left(z_{i}\right)$ but it clearly applies to both profiles) are specified from experience with simulated LIO retrieval performance for these two species so far. This indicated a characteristic height dependence of the two errors relative to each other. This dependence can be embodied into a simple static error model following the empirical vertical error modeling approach developed in the GRO context by Steiner and
Kirchengast (2005) and recently also adopted by ScherllinPirscher et al. (2011). This simple model can be written as

$\varepsilon_{\mathrm{CO}_{2}}\left(z_{i}\right)= \begin{cases}\varepsilon_{0}+q_{0}\left[\frac{1}{z_{i}^{p}}-\frac{1}{z_{\text {Ttop }}^{p}}\right], & \text { for } z_{\min }<z_{i} \leq z_{\text {Ttop }} \\ \varepsilon_{0}, & \text { for } z_{\text {Ttop }}<z_{i}<z_{\text {Sbot }} \\ \varepsilon_{0} \exp \left[\frac{\left(z_{i}-z_{\text {Sbot }}\right.}{H_{\mathrm{S}}}\right], & \text { for } z_{\text {Sbot }} \leq z_{i}<z_{\max }\end{cases}$

It models the errors as constant $\left(\varepsilon_{0}\right.$ in $\left.\%\right)$ in an UTLS core region, with an exponential increase defined by an error scale height $H_{\mathrm{S}}$ above this region, and with an increase by an inverse altitude law, defined in shape by $q_{0}$ and by the power parameter $p$ of $z$, below this region. For a more detailed discussion see Steiner and Kirchengast (2005) and ScherllinPirscher et al. (2011). Roughly reflecting the ${ }^{12} \mathrm{CO}_{2}$ and ${ }^{13} \mathrm{CO}_{2}$ VMR errors estimated in initial performance analyses we set the model parameters to $z_{\min }=0.5 \mathrm{~km}, z_{\mathrm{Ttop}}=15 \mathrm{~km}$, $z_{\text {Sbot }}=25 \mathrm{~km}, z_{\max }=80 \mathrm{~km}, \varepsilon_{0}=1.0 \%$ for ${ }^{12} \mathrm{CO}_{2}$ and $0.5 \%$ for ${ }^{13} \mathrm{CO}_{2}, q_{0}=10 \%$ for ${ }^{12} \mathrm{CO}_{2}$ and $15 \%$ for ${ }^{13} \mathrm{CO}_{2}, p=0.5$ for both isotopes, and $H_{\mathrm{S}}=18 \mathrm{~km}$ for ${ }^{12} \mathrm{CO}_{2}$ and $12 \mathrm{~km}$ for ${ }^{13} \mathrm{CO}_{2}$. Additionally, the resulting error $\varepsilon_{\mathrm{CO}_{2}}\left(z_{i}\right)$ is bounded to a maximum of $10 \%$, which is a reasonable bound becoming effective below a height of $1 \mathrm{~km}$ (practically irrelevant in the context here) and above $60 \mathrm{~km}$.

The two error profiles are illustrated in Fig. 7a for the altitude range of main interest. Figure $7 \mathrm{~b}$ shows the corresponding errors of the retrieved VMR profiles of ${ }^{12} \mathrm{CO}_{2},{ }^{13} \mathrm{CO}_{2}$, and of the composite $\mathrm{CO}_{2}$ VMR profile obtained according to Eqs. (19) and (20). The effect of more equal weighting is visible in particular at altitudes below about $10 \mathrm{~km}$, where the two individual errors are comparable. At higher altitudes, the composite is dominated by the lower ${ }^{13} \mathrm{CO}_{2}$ VMR error but the ${ }^{12} \mathrm{CO}_{2}$ VMR error is clearly seen to aid as well, especially if the two errors are incidentally opposite in sign such as above $30 \mathrm{~km}$. Overall the quality of the composite $\mathrm{CO}_{2}$ profile is clearly improved over either individual profile, staying unbiased with a standard deviation of less than $1 \%$ over most of the altitude range.

\section{$\mathrm{H}_{2} \mathrm{O}$ composite profile and its weighting}

The VMR profile of $\mathrm{H}_{2} \mathrm{O}$ is composed of the four $\mathrm{H}_{2} \mathrm{O}(X)$ $(X=\{1,2,3,4\})$ single-line species VMR profiles, which exhibit their respective best sensitivities in different height ranges. Hence the composite $\mathrm{H}_{2} \mathrm{O}$ profile can be expected to be very accurate throughout the whole UTLS whereas a single profile is accurate only in a limited height range (cf. Table 1 ; typical validity height range per $\mathrm{H}_{2} \mathrm{O}$ channel quoted in brackets). Since the composite $\mathrm{H}_{2} \mathrm{O}$ profile consists of profiles having the same isotope abundance, Eq. (17) turns for $\chi_{\mathrm{H}_{2} \mathrm{O}}\left(z_{i}\right)$ into the simple form

$\chi_{\mathrm{H}_{2} \mathrm{O}}\left(z_{i}\right)=\frac{1}{a_{\mathrm{H}_{2}^{16} \mathrm{O}}} \sum_{m=1}^{4}\left(w_{\mathrm{m}}\left(z_{i}\right) \chi_{\mathrm{H}_{2} \mathrm{O}(m)}\left(z_{i}\right)\right)$,

where $a_{\mathrm{H}_{2}^{16} \mathrm{O}}=0.997317$ after Rothman et al. (2005). 

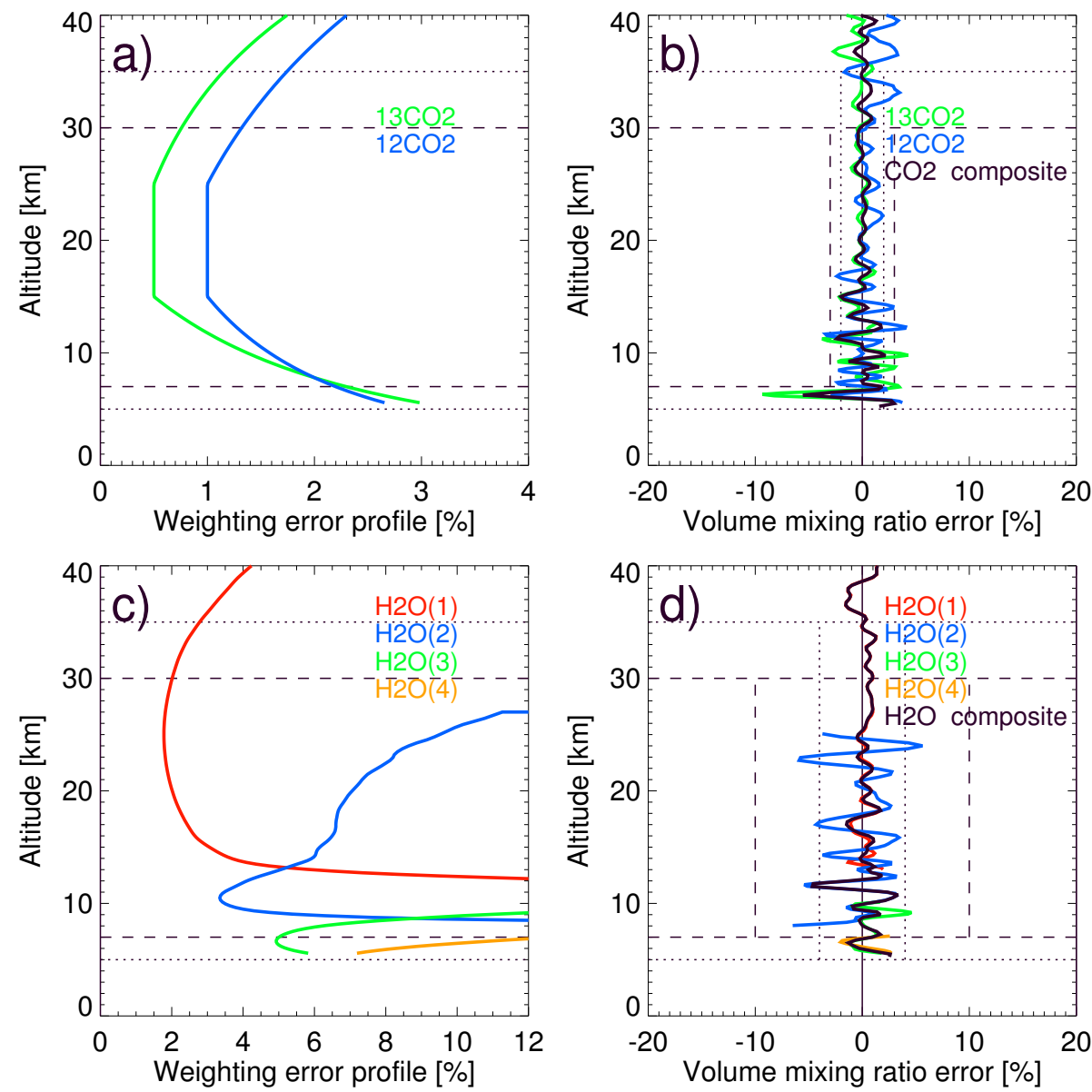

Fig. 7. Ilustration of combining the ${ }^{12} \mathrm{CO}_{2}$ and ${ }^{13} \mathrm{CO}_{2}$ VMR profiles into a composite $\mathrm{CO}_{2}$ profile (top panels), and of the four $\mathrm{H}_{2} \mathrm{O}(X)$ $(X=\{1,2,3,4\})$ VMR profiles into a composite $\mathrm{H}_{2} \mathrm{O}$ profile (bottom panels). The left panels (a, c) show the weighting error profiles used within the respective weighting functions for inverse-variance-weighted combination of the profiles (different color per single-line species). The right panels $(\mathbf{b}, \mathbf{d})$ show the VMR retrieval error results of the individual single-line species (colored lines) overplotted by the error of the composite profile (black line).

In this case, the relative VMR error profiles $\varepsilon_{\mathrm{H}_{2} \mathrm{O}}\left(z_{i}\right)$ in $\%$ for the four individual profiles need a dynamical error model, since $\mathrm{H}_{2} \mathrm{O}$ is a highly variable species (also here we supress the index $m$ in formulating $\varepsilon_{\mathrm{H}_{2} \mathrm{O}}\left(z_{i}\right)$ but it clearly applies to all four profiles). We follow the semi-analytical retrieval error propagation modeling in the simplified LIO performance simulator tool ALPS (Kirchengast et al., 2010b), which was described most accurately recently by Kirchengast and Schweitzer (2011). In particular, a reasonable simple estimate of the error profiles is given by the ratio of an empirically approximated absolute transmission error profile $\left(\mathcal{E}_{\mathcal{T}}\left(z_{i}\right)\right)$ in $\mathrm{dB}$ and the retrieved target species absorption loss profile $\left|\mathcal{T}_{\text {tgt }}\left(z_{i}\right)\right|$ in $\mathrm{dB}$ (cf. Sect. 3.4.2) in the form

$\varepsilon_{\mathrm{H}_{2} \mathrm{O}}\left(z_{i}\right)=100 \frac{\mathcal{E}_{\mathcal{T}}\left(z_{i}\right)}{\left|\mathcal{T}_{\text {tgt }}\left(z_{i}\right)\right|}$, where the factor 100 is to provide units $\%$. The absolute error profile $\mathcal{E}_{\mathcal{T}}\left(z_{i}\right)$ in Eq. (22) is formulated as

$\mathcal{E}_{\mathcal{T}}\left(z_{i}\right)=c_{\mathrm{f} 2 \mathrm{~dB}}\left[10^{-\left(\frac{\mathrm{SNR}_{\mathrm{Abs}}\left(z_{i}\right)}{10}\right)}+\mathcal{E}_{\mathcal{T}, \text { resid }}\right]$,

where $\operatorname{SNR}_{\mathrm{Abs}}\left(z_{i}\right)$ in $\mathrm{dB}$ is an estimate of the signal-to-noise ratio profile of the absorption channel, $\mathcal{E}_{\mathcal{T} \text {,resid }}$ is a fractional residual error set to 0.003 (lower bound error at high altitudes), and $c_{\mathrm{f} 2 \mathrm{~dB}}=4.3429 \mathrm{~dB} / 1$ is the conversion factor from fractional values to units $\mathrm{dB}$. The $\mathrm{SNR}$ profile $\operatorname{SNR}_{\mathrm{Abs}}\left(z_{i}\right)$ in Eq. (23) is dynamically estimated as

$\operatorname{SNR}_{\text {Abs }}\left(z_{i}\right)=\operatorname{SNR}_{\mathrm{TOA}}-\mathcal{L}_{\text {bgr }}\left(z_{i}\right)-\left|\mathcal{T}_{\text {tgt }}\left(z_{i}\right)\right|$,

where $\mathrm{SNR}_{\mathrm{TOA}}$ is the top-of-atmosphere value of the SNR set to $33 \mathrm{~dB}$ (an adequate value at TOA where transmission is unity; e.g., Kirchengast et al., 2010a; Kirchengast and Schweitzer, 2011), $\mathcal{L}_{\mathrm{bgr}}\left(z_{i}\right)$ in $\mathrm{dB}$ is a simple estimate of the total background loss profile, and definitely also the 
target species absorption loss profile $\left|\mathcal{T}_{\text {tgt }}\left(z_{i}\right)\right|$ needs to be subtracted to have a reasonable estimate of the total SNR profile $\operatorname{SNR}_{\mathrm{Abs}}\left(z_{i}\right)$. The background loss profile $\mathcal{L}_{\text {bgr }}\left(z_{i}\right)$ can be approximated by the dominating contribution of defocusing loss (cf. Schweitzer et al., 2011a) for which a simple exponential model in units $\mathrm{dB}$ following Kirchengast et al. (2010b) is

$\mathcal{L}_{\text {bgr }}\left(z_{i}\right)=\mathcal{L}_{0} \exp \left[-\frac{\left(z_{i}-z_{0}\right)}{H_{\text {loss }}}\right]$,

where $\mathcal{L}_{0}$ set to $10 \mathrm{~dB}$ is the estimated value of $\mathcal{L}_{\text {bgr }}$ at the base height $z_{0}=0 \mathrm{~km}$ and where the defocusing loss scale height $H_{\text {loss }}$ is set to $11 \mathrm{~km}$.

Briefly to explain the behavior of the model $\varepsilon_{\mathrm{H}_{2} \mathrm{O}}\left(z_{i}\right)$ according to Eqs. (22) to (25), the absolute error profile $\mathcal{E}_{\mathcal{T}}\left(z_{i}\right)$ in the numerator is basically dominated by the (decaying) background loss profile $\mathcal{L}_{\text {bgr }}\left(z_{i}\right)$ at higher altitudes and by the increasingly growing absorption loss profile $\left|\mathcal{T}_{\text {tgt }}\left(z_{i}\right)\right|$ at lower altitudes. The absorption loss in the denominator does not grow as fast downwards as the absolute error in the numerator, however, so that also the relative error $\varepsilon_{\mathrm{H}_{2} \mathrm{O}}\left(z_{i}\right)$ strongly increases downwards when absorption in a channel becomes strong. On the other hand $\varepsilon_{\mathrm{H}_{2} \mathrm{O}}\left(z_{i}\right)$ increases as well towards higher altitudes since the absorption loss in the denominator becomes small upwards faster than the absolute error. In order to limit the error below and above the height range where a particular channel is most sensitive, we keep $\varepsilon_{\mathrm{H}_{2} \mathrm{O}}\left(z_{i}\right)$ in practice constant at altitudes, where the respective absorption loss profile is outside $0.25 \mathrm{~dB}$ to $17 \mathrm{~dB}$ (setting the constant to the error value at the altitudes associated with these two threshold values). This ensures sufficient overlap between the channels at all heights and at the same time overall robustness of this dynamical composite profile estimation.

Figure $7 \mathrm{c}$ shows the resulting error profiles for the four $\mathrm{H}_{2} \mathrm{O}(X)$ profiles with $X=\{1,2,3,4\}$. The altitude regions with the best sensitivity of the channels are clearly visible as is the general altitude-dependent behavior described above; the contribution of the $\mathrm{H}_{2} \mathrm{O}(4)$ channel is limited in this STD atmosphere case, its value is to support the very moist tropical conditions. An illustration of the corresponding errors of the VMR profiles of the four $\mathrm{H}_{2} \mathrm{O}$ single-line retrievals and of the composite $\mathrm{H}_{2} \mathrm{O}$ VMR profile is given in Fig. 7d. The benefit of the weighted profile combination is well visible, since it is clearly seen that the composite profile is very effective in exploiting at all altitude levels the best possible information. In this way the overall quality of the composite $\mathrm{H}_{2} \mathrm{O}$ profile is substantially improved over either individual profile, staying unbiased and reaching a standard deviation of within $2 \%$ essentially everywhere in the altitude range.

\subsection{Basic-update-control (BUC) runs}

The last step of the LIO retrieval is the outer loop, also called Basic-Update-Control run (BUC) loop. This loop is a simple envelope loop over the MSR process, as shown in Fig. 3, to guarantee (update run) and cross-check (control run) the convergence of the retrieved set of GHG/isotope profiles beyond the first complete step of the loop (basic run). Each of these runs consists of a full MSR process, including all trace species retrieved by the SSR core process in the well defined order presented in Sect. 3.5.1, and including the generation of the composite $\mathrm{CO}_{2}$ and $\mathrm{H}_{2} \mathrm{O}$ profiles. After the basic run, all initial/background GHG profiles are replaced by the retrieved GHGs, followed by the update run after which the GHG/isotope profiles are improved and the retrieval results have nominally fully converged. The control run provides quantitative quality control of the convergence of every single retrieved GHG profile over the full altitude range.

To provide an example of the effectiveness of the BUC loop, the output VMR profiles after each step of the loop are illustrated for $\mathrm{CH}_{4}$ and $\mathrm{H}_{2} \mathrm{O}$ in Fig. 8 and for $\mathrm{CO}_{2}$ and $\mathrm{O}_{3}$ in Fig. 9, for three representative atmospheric conditions. It is clearly seen that already the update run ensures full convergence for all species, which is verified by the control run result; details on these demonstration results are discussed in Sect. 4.

Regarding finally the computational efficiency of the complete LMIO retrieval algorithm in the EGOPS/xEGOPS system (LMO thermodynamic state retrieval and afterwards LIO multi-species retrieval with full BUC loop), it currently takes without any dedicated speed optimization effort and without compiler optimization about 30 min on a standard Linux workstation of the $2 \mathrm{GHz}$ CPU class (the most demanding part being the RFM transmission computations for foreign species correction). Given the multi-parameter retrieval power and substantial room for speed improvements, this computational performance is very encouraging. It is clear that all data of any real LMIO mission could be readily processed within adequate time slots with a very moderate number of processors.

\section{Demonstration results}

Here we discuss the retrieval demonstration results of the set of representative example species of this study $\left(\mathrm{CO}_{2}, \mathrm{H}_{2} \mathrm{O}\right.$, $\mathrm{CH}_{4}, \mathrm{O}_{3}$ ); a more complete analysis comprising all LIO species and statistical retrieval performance estimates from ensemble simulations is on-going and will be published elsewhere. Figures 8 and 9 illustrate the GHG profiles retrieval performance achieved for $\mathrm{CH}_{4}, \mathrm{H}_{2} \mathrm{O}, \mathrm{CO}_{2}$, and $\mathrm{O}_{3}$ by the LMIO retrieval after each run of the BUC loop in terms of VMR retrieval errors against the "true" VMR profiles used in the forward modeling. Intentionally the order of showing the results of the four species follows the sequence as they are retrieved within the MSR loop, facilitating to see (small) influences of whether a species is retrieved earlier or later. Three representative atmospheric conditions are considered (top to bottom in Figs. 8 and 9), the sub-arctic winter (SAW), 

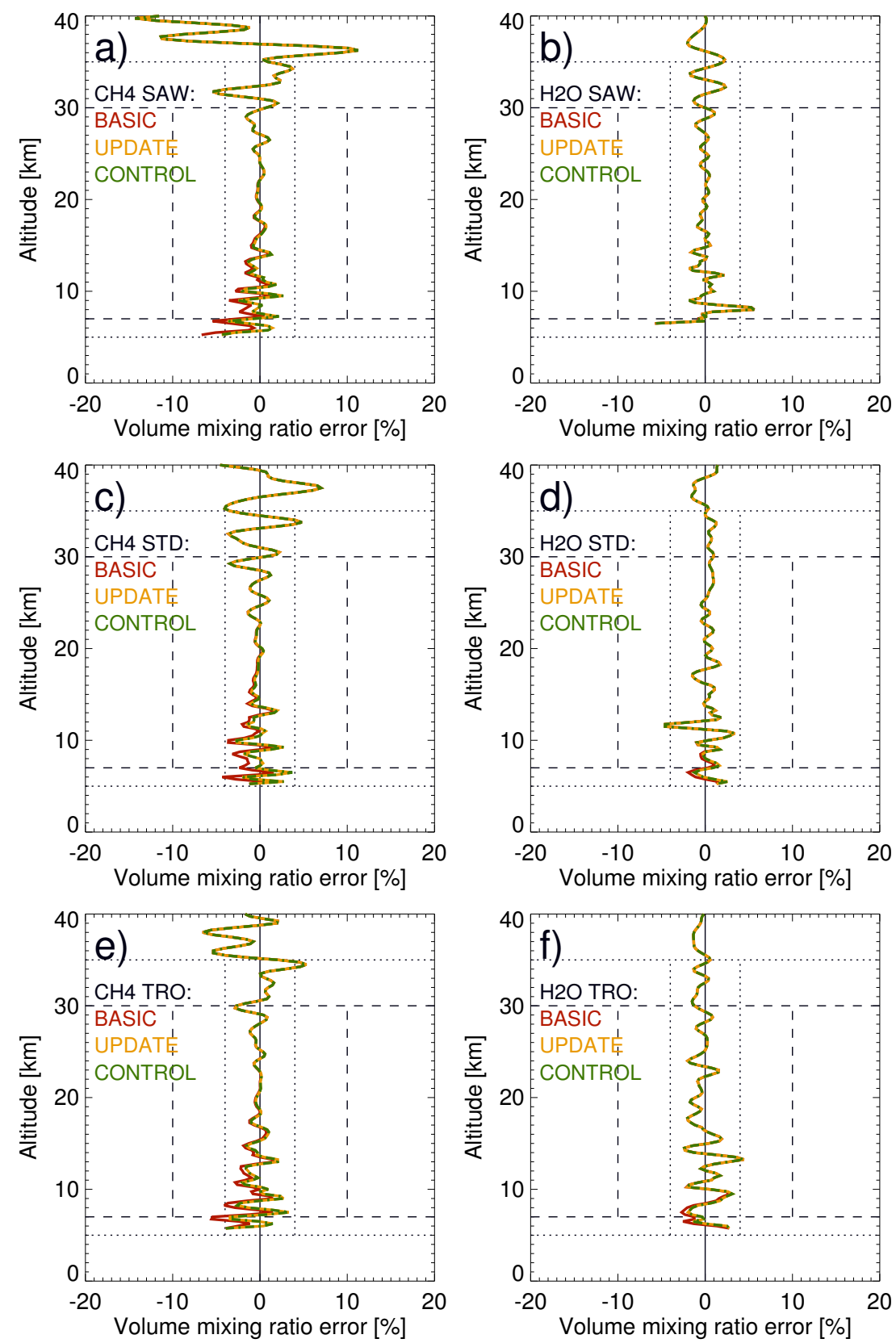

Fig. 8. Retrieval performance results of the LMIO end-to-end simulations for $\mathrm{CH}_{4}$ (left column) and $\mathrm{H}_{2} \mathrm{O}$ (right column). VMR retrieval errors are shown for sub-arctic winter (top), standard (middle), and tropical (bottom) atmosphere conditions, for GHG retrieval results after the basic run (red line), update run (yellow line) and control run (green dashed-dotted line) of the basic-update-control run (BUC) loop.

standard (STD), and tropical (TRO) atmospheres of the FASCODE model (Anderson et al., 1986; FASCODE, 2008; with the $\mathrm{CO}_{2} \mathrm{VMR}$ updated to $380 \mathrm{ppmv}$ as noted in Sect. 2.2).

For these demonstration cases, we subsequently retrieved the single-line species $\mathrm{CH}_{4},{ }^{13} \mathrm{CO}_{2}, \mathrm{H}_{2} \mathrm{O}(X)(X=\{1,2,3$, $4\}),{ }^{12} \mathrm{CO}_{2}$, and $\mathrm{O}_{3}$ by use of the MSR process, with the SSR process embedded, in each run of the BUC loop. While $\mathrm{CH}_{4}$ and $\mathrm{O}_{3}$ are single-line species, i.e., derived from a single channel pair utilizing a single absorption line, $\mathrm{CO}_{2}$ and $\mathrm{H}_{2} \mathrm{O}$ are composite profiles as discussed in Sect. 3.5.
The initial values for the four GHG profiles demonstrated here were set to zero to illustrate a "worst case" initialization. The other two initial/background GHG profiles needed $\left(\mathrm{N}_{2} \mathrm{O}, \mathrm{CO}\right)$ were set to their GHG values from the respective FASCODE atmosphere as we did not focus on these two here; their influence as foreign species is very small anyway (Schweitzer, 2010) and their effects on the retrieval of the four example species generally negligible even if only rough knowledge of their concentrations is used. 

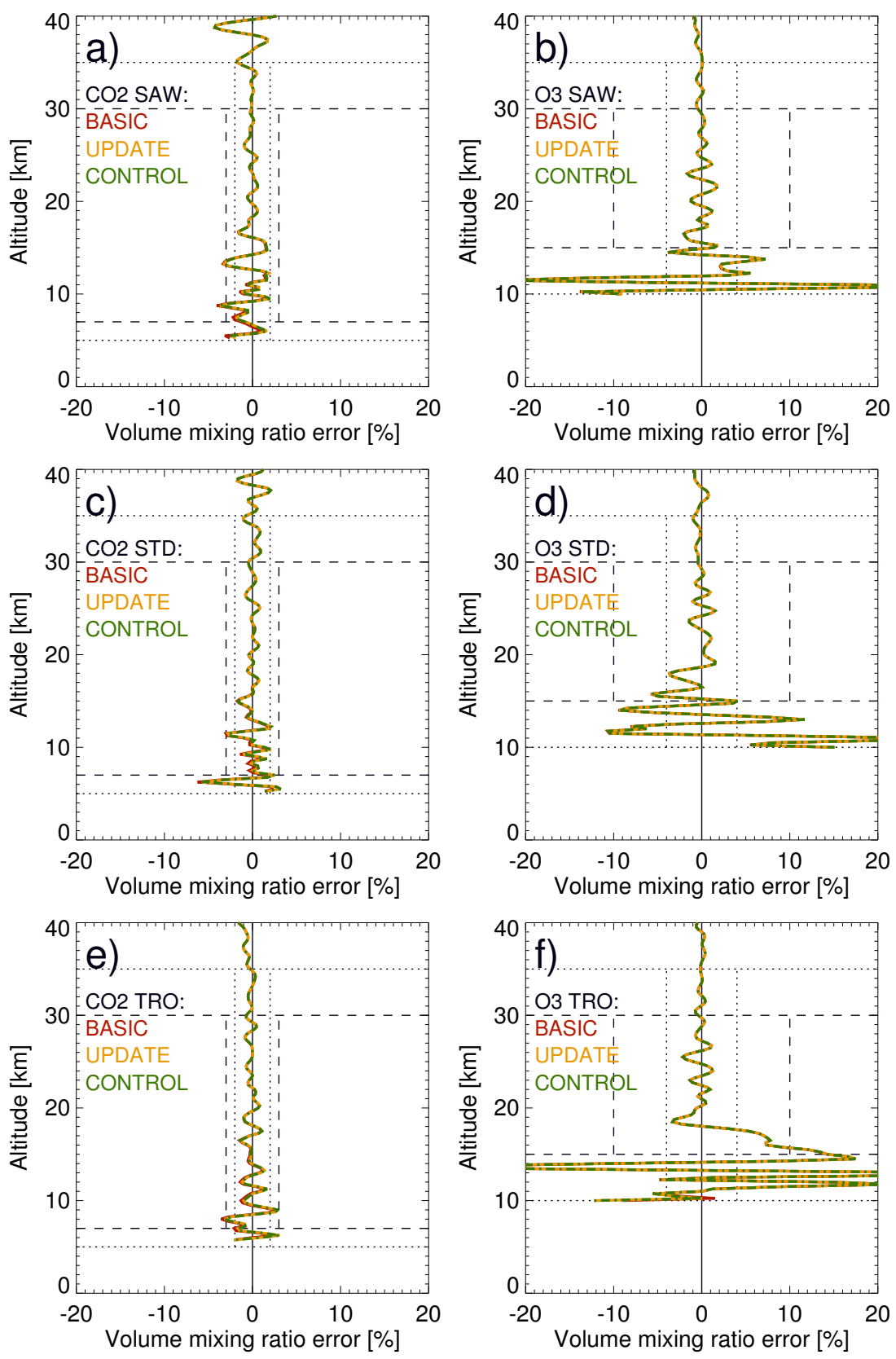

Fig. 9. Retrieval performance results of the LMIO end-to-end simulations for $\mathrm{CO}_{2}$ (left column) and $\mathrm{O}_{3}$ (right column). The layout is the same as in Fig. 8; see that caption for explanation.

$\mathrm{CH}_{4}$ is the species retrieved first in the sequence and Fig. 8 (left column) shows the performance. Since the initial/background GHGs profiles at start of the basic run were zero, the foreign species correction necessarily yielded no appropriate estimate and indeed the $\mathrm{CH}_{4}$ error from the basic run shows a slight negative bias within $1 \%$ to $2 \%$ below about $12 \mathrm{~km}$ under all atmospheric conditions (red profile). That this bias is relatively small despite the foreign species effects are not corrected at all indicates the careful selection of very "clean" channels. However, as the LMIO method targets to keep biases within $0.1 \%$ to $0.2 \%$, a correction is clearly needed. It is seen that this correction is very effectively done by the update run (yellow dashed profile), for which all other GHGs are already available from the basic run. The control run (green dotted-dashed profile) then confirms that the $\mathrm{CH}_{4}$ error has converged to within the $0.1 \%$ level.

The single-line species next in sequence is ${ }^{13} \mathrm{CO}_{2}$, since it is helpful to have a first $\mathrm{CO}_{2}$ profile estimate (that itself is not sensitive to $\mathrm{H}_{2} \mathrm{O}$ ) before retrieving $\mathrm{H}_{2} \mathrm{O}$ (cf. the discussion of 
the sensitivity of $\mathrm{H}_{2} \mathrm{O}$ to $\mathrm{CO}_{2}$ in Sect. 3.5.1 and the related Fig. 6). This intermediate auxiliary single-line retrieval is followed by the retrieval of all four $\mathrm{H}_{2} \mathrm{O}$ single-line profiles and the computation of the related $\mathrm{H}_{2} \mathrm{O}$ composite profile for which the retrieval performance is shown in Fig. 8 (right column). Since for $\mathrm{H}_{2} \mathrm{O}$ the initial/background GHG profiles for $\mathrm{CH}_{4}$ and $\mathrm{CO}_{2}$ are available during the basic run, the performance of this basic run is very good already. Small biases are visible only below about $9 \mathrm{~km}$, especially for the moist tropical atmosphere, but staying within $1 \%$ even there. In the dry sub-arctic winter case, where the first two singleline retrievals $\mathrm{H}_{2} \mathrm{O}(1)$ and $\mathrm{H}_{2} \mathrm{O}(2)$ favorably reach with their sensitivity deeper into the upper troposphere, the retrieval is already fully converged in the basic run. As for $\mathrm{CH}_{4}$ the update run effectively corrects the remaining biases in the lowest part of the UTLS and leads to convergence to within the $0.1 \%$ level as confirmed by the control run.

The $\mathrm{CO}_{2}$ composite profile, which finishes retrieval as the third species next after $\mathrm{H}_{2} \mathrm{O}$, exhibits already very good performance from the basic run as illustrated in Fig. 9 (left column). Remaining biases relative to full convergence are at the order of $0.1 \%$ also everywhere below $10 \mathrm{~km}$. This is possible for $\mathrm{CO}_{2}$ because the foreign species correction can use the retrieved $\mathrm{CH}_{4}$ and $\mathrm{H}_{2} \mathrm{O}$ profiles as background in the basic run already. Only the initial/background GHG profile for $\mathrm{O}_{3}$ is still zero, but there is no relevant cross-sensitivity of $\mathrm{CO}_{2}$ to $\mathrm{O}_{3}$ (cf. Schweitzer, 2010; Schweitzer et al., 2011a). The update run very slightly changes the results from the basic run below about $10 \mathrm{~km}$ only and the control run again confirms the update run.

The species retrieved last is $\mathrm{O}_{3}$, the retrieval performance of which is shown in Fig. 9 (right column). Here the $\mathrm{O}_{3}$ VMR error resulting from the basic run is already fully converged as confirmed by the update and the control run; there is only one small bias visible from the basic run near $10 \mathrm{~km}$ in the tropical atmosphere, which points to the foreign influence of $\mathrm{H}_{2} \mathrm{O}$, being the key cross-sensitivity of the $\mathrm{O}_{3}$ channels used. The lower bound altitude domain requirements of $\mathrm{O}_{3}$ are higher than for the other species, since the ozone layer resides in the stratosphere and the concentration becomes weak towards the troposphere. Based on this the noise level starts to increase below about $15 \mathrm{~km}$ and further down below about $10 \mathrm{~km}$ also the $\mathrm{H}_{2} \mathrm{O}$ influence begins to mask the $\mathrm{O}_{3}$ absorption (Schweitzer, 2010; Schweitzer et al., 2011a). The $\mathrm{O}_{3}$ channels thus focus on accurate profiling of stratospheric ozone from about $10 \mathrm{~km}$ to $15 \mathrm{~km}$ upwards.

Considering finally the overall GHG retrieval performance indicated by these intial demonstration results of the new LMIO algorithm it looks very encouraging. The results from these quasi-realistic end-to-end simulations are consistent with and confirm the basic estimates from simplified error propagation modeling by Kirchengast and Schweitzer (2011). The retrieval errors appear to be essentially unbiased over the full height range of interest and the r.m.s. errors appear to lie well within target requirements. Since the errors are essentially random, climatological averages will enable very high accuracy at the $0.1 \%$ level, given sufficient care is taken related to avoiding or mitigating potential systematic errors in all relevant elements of an LMIO mission design as dicussed by Kirchengast et al. (2010a) and Kirchengast and Schweitzer (2011).

Favorably $\mathrm{CO}_{2}$ appears to be the GHG that can be retrieved most accurately, within $1 \%$ to $2 \%$ of VMR error, but also the other species $\mathrm{H}_{2} \mathrm{O}, \mathrm{CH}_{4}$ and $\mathrm{O}_{3}$ are retrieved to within $1 \%$ to $3 \%$ of VMR error almost everywhere in their targeted altitude domain. Specifically regarding $\mathrm{H}_{2} \mathrm{O}$, the results indicate that it can be retrieved in clear air from LIO with significantly more accuracy than from LMO (the latter yields to within about $10 \%$; e.g., Schweitzer et al., 2011b). Thus LIO could also help to further improve the accuracy of the thermodynamic state $p, T, q$. For $\mathrm{O}_{3}$ the retrieval strength lies in the stratosphere from about $15 \mathrm{~km}$ upwards.

\section{Summary and conclusions}

In this study we introduced a retrieval algorithm for the LIO part of the LMIO satellite mission concept, which is a proposed occultation observing system that combines LIO and LMO to retrieve thermodynamic profiles (pressure, temperature, humidity) as a function of altitude from LMO and GHG profiles from simultaneously measured LIO data. The LMO algorithm part for thermodynamic state retrieval was recently introduced by Schweitzer et al. (2011b), the novel LMIO method as a whole by Kirchengast and Schweitzer (2011). The LIO algorithm, completing the full LMIO retrieval, is applied as a second step after the LMO algorithm. We described the LIO algorithm in detail and showed its performance - and the effective independence of the GHG retrieval results from external (a priori) information - via demonstration results from LMIO end-to-end simulations by the EGOPS/xEGOPS software system for a representative set of $\mathrm{GHG}$ profiles $\left(\mathrm{CO}_{2}, \mathrm{H}_{2} \mathrm{O}, \mathrm{CH}_{4}\right.$, and $\left.\mathrm{O}_{3}\right)$ under three representative clear-air atmospheric conditions (tropical, standard, sub-arctic winter).

We showed how the LIO algorithm benefits from the LMO output, more precisely from the thermodynamic profiles (pressure, temperature, humidity) and the impact parameter profile, the latter enabling acccurate geolocation of altitude levels. The LIO intensity signals as a function of time, complemented by initial/background GHG profiles which can even be set to zero initially, are the LIO observational input to the algorithm. The algorithm itself consists of a preparatory part, establishing IR refractivity, impact parameter, and altitude profiles from LMO output, a core part, the single-line trace species retrieval (SSR), and a dynamic part of envelope loops over the SSR, consisting of the multi-line trace species retrieval (MSR) loop and the basic-update-control run (BUC) loop, respectively. 
The preparatory part establishes the IR refractivity, IR impact parameter, and IR altitude profiles corresponding to the transmitter and receiver positions and the LIO intensity profiles available as a function of time. The SSR provides trace species volume mixing ratio (VMR) profiles from single absorption lines, i.e., from the LIO intensities of a single pair of absorption and reference channel, by exploiting the differential absorption principle which enables high-accuracy retrievals.

The MSR loop, an envelope process over the SSR process, performs single-line species retrievals in a carefully defined order and updates the set of initial/background GHG profiles after each SSR step, resulting in a step-wise improved set of GHG profiles. A proper order provides highly effective retrieval and enables to start even with initial profiles set to zero: we first retrieve the most independent species (in terms of minimal absorption influence in their channels from other species), followed by the less independent ones that can then already benefit from the previously retrieved ones in their correction for residual foreign species absorption. In addition, the MSR combines suitable single-line species profiles into composite profiles, which we employed for a composite $\mathrm{CO}_{2}$ profile from ${ }^{12} \mathrm{CO}_{2}$ and ${ }^{13} \mathrm{CO}_{2}$ and for a composite $\mathrm{H}_{2} \mathrm{O}$ profile from the four $\mathrm{H}_{2} \mathrm{O}$ single-line profiles of which each only partially covers the UTLS altitude range.

The BUC loop is a simple envelope loop over the MSR process to complete (update run) and cross-check (control run) the convergence of the retrieved set of GHG profiles after the first MSR run (basic run).

Regarding the EGOPS/xEGOPS end-to-end simulations, the GHG retrieval performance indicated by the intial demonstration results of the LMIO algorithm were found very encouraging. The results are consistent with and confirm the basic estimates from simplified error propagation modeling by Kirchengast and Schweitzer (2011). The retrieval errors appear to be essentially unbiased over the full height range of interest and the r.m.s. errors appear to lie well within target requirements set by scientific objectives of atmosphere and climate research to be supported by the data.

Carbon dioxide appears to be the GHG that can be retrieved most accurately, within $1 \%$ to $2 \%$ of VMR error, but also the other species $\mathrm{H}_{2} \mathrm{O}, \mathrm{CH}_{4}$ and $\mathrm{O}_{3}$ are retrieved to within $1 \%$ to $3 \%$ of VMR error almost everywhere in their targeted altitude domain. The $\mathrm{H}_{2} \mathrm{O}$ results indicate that water vapor can be retrieved in clear air from LIO with higher accuracy than from LMO so that LIO could also potentially help this way to further improve the accuracy of the thermodynamic state. For $\mathrm{O}_{3}$ the retrieval strength is on the stratospheric ozone from about $15 \mathrm{~km}$ upwards as the $\mathrm{O}_{3}$ signalto-noise ratio becomes small below about $10 \mathrm{~km}$ to $15 \mathrm{~km}$.

Since the individual-profile errors found here are essentially random, climatological averages will enable very high accuracy at the $0.1 \%$ level, given sufficient care is taken related to avoiding or mitigating potential systematic errors in all relevant elements of an LMIO mission design as dicussed by Kirchengast et al. (2010a) and Kirchengast and Schweitzer (2011). Overall the LMIO retrieval performance, found here for clear-air atmospheric conditions, is unprecedented for vertical profiling of GHGs in the free atmosphere and encouraging for future LMIO implementation.

On-going subsequent work includes a more complete performance analysis, comprising all LIO species and statistical retrieval error estimates from end-to-end ensemble simulations, also using a greater variety of atmospheric conditions. Further work addresses the advancement of the present GHG retrieval algorithm to cloudy air, for best-possible retrieval performance also when scanning through intermittent upper tropospheric cloudiness, as well as the advancement of the retrieval to also determine line-of-sight wind speed beyond the simple approach introduced by Schweitzer (2010) and Kirchengast and Schweitzer (2011). On the experimental side a ground-based LIO demonstration experiment is carried out for a $144 \mathrm{~km}$ link between high-altitude observatories at the Canary Islands, Spain (ESA project by Univ. of York, Univ. of Manchester, and Univ. of Graz, P. F. Bernath et al., 2010-2011). This work aims at a first experimental demonstration of the $\mathrm{LIO}$ technique for $\mathrm{CO}_{2}, \mathrm{CH}_{4}$, and $\mathrm{H}_{2} \mathrm{O}$ measurements under field conditions somewhat akin to a space link.

Acknowledgements. We thank J. Fritzer and M. Schwärz for commenting on the manuscript of the paper and for contributions to EGOPS/xEGOPS developments. EGOPS was developed by an international consortium led by UniGraz (AT) and involving partners at Danish Meteorol Inst. (DK), Obukhov Inst. of Atmos. Physics (RU), Chalmers Univ. of Technology (SE), Univ. of Bremen (DE), Met. Office (UK), Terma Elektronik A/S (DK), and RUAG Space GmbH (AT). xEGOPS was developed by UniGraz (AT), with contributions by E. Martini (CNIT, IT) and V. Sofieva (FMI, FI) to scintillation modeling and by C. Emde (Univ. of Munich, DE) to cloud extinction modeling. Funds for the EGOPS/xEGOPS development were provided by ESA/ESTEC (NL), FWF and FFG-ALR (AT), and EUMETSAT/HQ (DE). RFM and FASCODE were provided by A. Dudhia (Univ. of Oxford, UK) via www.atm.ox.ac.uk/RFM, and HITRAN was provided by L. Rothman (Harvard Univ., USA) via www.cfa.harvard.edu/hitran. This study was funded by ESA/ESTEC (NL) under the GSPACTLIMB and STSE-IRDAS studies and partially by FFG-ALR (AT) under the ASAP-ACCU-Clouds study.

Edited by: K. B. Lauritsen 


\section{References}

Allison, C. E. and Francey, R. J.: Verifying southern hemisphere trends in atmospheric carbon dioxide stable isotopes, J. Geophys. Res., 112, D21304, doi:10.1029/2006JD007345, 2007.

Anderson, G. P., Clough, S. A., Kneizys, F. X., Chetwynd, J. H., and Shettle, E. P.: AFGL atmospheric constituent profiles (0120 km), Environm. Res. Papers, Tech. Rep. 954, AFGL-TR-860110, Optical Phys. Div., Air Force Geophys. Lab., Hanscom AFB, Massachusetts, USA, 1986.

Anthes, R. A., Ector, D., Hunt, D. C., Kuo, Y.-H., Rocken, C., Schreiner, W. S., Sokolovskiy, S. V., Syndergaard, S., Wee, T.K., Zeng, Z., Bernhardt, P. A., Dymond, K. F., Chen, Y., Liu, H., Manning, K., Randel, W. J., Trenberth, K. E., Cucurull, L., Healy, S. B., Ho, S.-P., McCormick, C., Meehan, T. K., Thompson, D. C., and Yen, N. L.: The COSMIC/FORMOSAT3 mission: Early results, B. Am. Meteorol. Soc., 89, 313-333, doi:10.1175/BAMS-89-3-313, 2008.

Bönsch, G. and Potulski, E.: Measurements of the refractive index of air and comparison with modified Edlén's formulae, Metrologia, 35, 133-139, 1998.

Born, M. and Wolf, E.: Principles of Optics, Pergamon Press, New York, 1964.

Dudhia, A.: Reference Forward Model RFM: Inst. of Atmos., Oceanic, and Planet. Phys., Univ. of Oxford, Oxford, UK, http: //www.atm.ox.ac.uk/RFM/ (last access: 18 April 2011), 2008.

Edlén, B.: The refractive index of air, Metrologia, 2, 71-80, 1966.

Edwards, D. P.: High level algorithm definition document, Tech. Rep. ESA/ESTEC PO-TN-OXF-GS-0004, Contract No. 11886/96/NL/GS, Inst. of Atmos., Oceanic, and Planet. Phys., Univ. of Oxford, Oxford, UK, 1996.

Emde, C. and Proschek, V.: Atmospheric impacts on ILO signals: Impact of cloud scattering, Tech. Rep. for ESA-ESTEC Technical Note 2 - Part of the TR-IRPERF Report, DLR Oberpfaffenhofen, Wessling, Germany, 2010.

FASCODE: RFM website - FASCODE model atmospheres, Inst. of Atmos., Oceanic, and Planet. Phys., Univ. of Oxford, Oxford, UK, http://www.atm.ox.ac.uk/RFM/atm (last access: 18 April 2011), 2008.

Fjeldbo, G. and Eshleman, V. R.: The bistatic radar-occultation method for the study of planetary atmospheres, J. Geophys. Res., 70, 3217-3225, 1965.

Fjeldbo, G., Kliore, A. J., and Eshleman, V. R.: The neutral atmosphere of venus as studied with the Mariner V radio occultation experiments, Astron. J., 76, 123-140, 1971.

Fritzer, J. M., Kirchengast, G., and Pock, M.: End-to-End Generic Occultation Performance Simulation and Processing System version 5.5 (EGOPS 5.5) Software User Manual, Tech. Rep. ESAESTEC WEGC-EGOPS-2009-TR01, Wegener Center and Inst. for Geophys., Astrophys., and Meteorol., Univ. of Graz, Graz, Austria, 2009.

Fritzer, J. M., Kirchengast, G., Pock, M., and Proschek, V.: Endto-End Generic Occultation Performance Simulation and Processing System version 5.5 (EGOPS 5.5 and xEGOPS) Software User Manual, Tech. Rep. ESA-ESTEC WEGC-EGOPS-2010TR01, Wegener Center and Inst. for Geophys., Astrophys., and Meteorol., Univ. of Graz, Graz, Austria, 2010.

Fuchs, K. and Stoffel, H.: Landolt-Börnstein: Numerical Data and Functional Relationships in Science and Technology - Geophysics of the Solid Earth, the Moon and the Planets, vol. 2a,
Springer Verlag, Berlin-Heidelberg, 1984.

Gorbunov, M. E. and Kirchengast, G.: Processing X/K band radio occultation data in the presence fo turbulence, Radio Sci., 40, RS6001, doi:10.1029/2005RS003263, 2005.

Gorbunov, M. E. and Kirchengast, G.: Fluctuations of radio occultation signals in $\mathrm{X} / \mathrm{K}$ band in the presence of anisotropic turbulence and differential transmission retrieval performance, Radio Sci., 42, RS4025, doi:10.1029/2006RS003544, 2007.

Harrison, J. J., Bernath, P. F., and Kirchengast G.: Spectroscopic requirements for ACCURATE, a microwave and infrared-laser occultation satellite mission, J. Quant. Spectrosc. Ra., 112, 2347 2354, doi:10.1016/j.jqsrt.2011.06.003, 2011.

Herman, B. M., Feng, D., Flittner, D., Kursinski, E. R., Syndergard, S., and Ward, D.: An overview of the University of Arizona ATMOS project, in: Occultations for Probing Atmosphere and Climate, edited by: Kirchengast, G., Foelsche, U., and Steiner, A. K., Springer Verlag, Berlin, 189-200, 2004.

Ho, S.-P., Kirchengast, G., Lero, S., Wickert, J., Mannuci, A. J., Steiner, A. K., Hunt, D., Schreiner, W., Sokolovskiy, S., Ao, C., Borsche, M. W., von Engeln, A., Foelsche, U., Heise, S., Lijima, B., Kuo, Y.-H., Kursinski, E. R., Pirscher, B., Ringer, M., Rocken, C., and Schmidt, T.: Estimating the uncertainty of using GPS radio occultation data for climate monitoring: Intercomparison of CHAMP refractivity climate records 2002-2006 from different data centers, J. Geophys. Res., 114, D23107, doi:10.1029/2009JD011969, 2009.

Jensen, A. S., Lohmann, M. S., Benzon, H.-H., and Nielsen, A. S.: Full spectrum inversion of radio occultation signals, Radio Sci., 38, 1040, doi:10.1029/2002RS002763, 2003.

Kirchengast, G.: End-to-End GNSS Occultation Performance Simulator functionality definition, Tech. Rep. ESA/ESTEC 1/1996, Inst. for Geophys., Astrophys., and Meteorol., Univ. of Graz, Graz, Austria, 1996.

Kirchengast, G.: End-to-End GNSS Occultation Performance Simulator overview and exemplary applications, Wiss. Ber. ESA/ESTEC 2/1998, Inst. for Geophys., Astrophys., and Meteorol., Univ. of Graz, Graz, Austria, 1998.

Kirchengast, G.: Occultations for probing atmosphere and climate: setting the scence, in: Occultations for Probing Atmosphere and Climate, edited by: Kirchengast, G., Foelsche, U., and Steiner, A. K., Springer Verlag, Berlin, 1-8, 2004.

Kirchengast, G. and Hoeg, P.: The ACE+ mission: An atmosphere and climate explorer based on GPS, GALILEO and LEO-LEO radio occultation, in: Occultations for Probing Atmosphere and Climate, edited by: Kirchengast, G., Foelsche, U., and Steiner, A. K., Springer Verlag, Berlin, 201-220, 2004.

Kirchengast, G. and Schweitzer, S.: Climate benchmark profiling of greenhouse gases and thermodynamic structure and wind from space, Geophys. Res. Lett., 38, L13701, doi:10.1029/2011GL047617, 2011.

Kirchengast, G., Fritzer, J. M., and Ramsauer, J.: End-to-End GNSS Occultation Performance Simulator version 4 (EGOPS4) Software User Manual, Tech. Rep. ESA/ESTEC 2/2002, Inst. for Geophys., Astrophys., and Meteorol., Graz, Austria, 2002.

Kirchengast, G., Schweitzer, S., Schwärz, M., and Gorbunov, M. E.: Advanced retrieval processing chain for derivation of atmospheric profiles from LEO-LEO radio occultation data, Tech. Rep. ESA/ESTEC 2/2006, Wegener Center, Univ. of Graz, Graz, Austria, 2006. 
Kirchengast, G., Schweitzer, S., Fritzer, J. M., and Ramsauer, J.: End-to-End Generic Occultation Performance Simulator version 5.2 (EGOPSv5.2) Software User Manual, Tech. Rep. ESA/ESTEC 4/2007, Wegener Center, Univ. of Graz, Graz, Austria, 2007.

Kirchengast, G., Bernath, P. F., Buehler, S., Durry, G., Facheris, L., Gerbig, C., Haimberger, L., Harris, J., Hauchecorne, A., Kurölä, E., Larsen, G. B., Sausen, R., Anthes, R. A., Gorbunov, M. E., Kursinski, E. R., Leroy, S. S., Trenberth, K., Randel, B., Gille, J., and Tsuda, T.: ACCURATE - climate benchmark profiling of greeenhouse gases and thermodynamic variables and wind from space (ESA Earth Explorer Opportunity Mission EE-8 proposal), Sci. Rep. No. 36, document wcv-scirep-no36-gkirchengastetaljul2010.pdf, Wegener Center Verlag, Graz, Austria, available at: http://www.wegcenter.at/wcv/ (last access: 18 April 2011), 2010a.

Kirchengast, G., Schweitzer, S., Proschek, V., González Abad, G., Li, G., Allen, N., Harrison, J., Thomas, B., and Bernath, P. F.: ALPS - ACCURATE LIO Performance Simulator - user guide and documentation, Tech. Rep. ESA-ESTEC 3/2010, Wegener Center, Univ. of Graz, Graz, Austria, 2010b.

Kursinski, E. R., Hajj, G. A., Schofield, J. T., Linfield, R. P., and Hardy, K. R.: Observing Earth's atmosphere with radio occultation measurements using the global positioning system, J. Geophys. Res., 102, 23429-23465, 1997.

Kursinski, E. R., Syndergaard, S., Flittner, D., Feng, D., Hajj, G., Herman, B., Ward, D., and Yunck, T.: A microwave occultation observing system optimized to characterize atmospheric water, temperature and geopotential via absorption, J. Atmos. Ocean. Tech., 19, 1897-1914, doi:10.1175/15200426(2002)019<1897:AMOOSO>2.0.CO;2, 2002.

Kursinski, E. R., Ward, D., Otarola, A., Frehlich, K., Groppi, C., Albanna, S., Shein, M., Bertiger, W., Pickett, H., and Ross, M.: The Active Temperature, Ozone and Moisture Microwave Spectrometer (ATOMMS), in: New Horizons in Occultation Research, edited by: Steiner, A. K., Pirscher, B., Foelsche, U., and Kirchengast, G., Springer Verlag, Berlin, 295-313, doi:10.1007978-3642-00312-9_24, 2009.

Larsen, G. B., Kirchengast, G., and Bernath, P. F.: Science objectives and observational requirements of the ACCURATE mission concept, Tech. Rep. DMI/ESA-IRDAS/ObsReq/Oct2009, Danish Meteorol. Inst., Copenhagen, Denmark, 2009.

Liebe, H. J., Hufford, G., and Cotton, M.: Propagation modeling of moist air and suspended water/ice particles at frequencies below $1000 \mathrm{GHz}$, in: AGARD Proc. Atmospheric Propagation Effects through Natural and Man-Made Obscurants for Visible to MM-Wave Radiation, edited by: Delfour, A., Guillame, B., and Junchat, A. P., NTIA, Boulder, CO, 3-1-3-10, 1993.

Luntama, J.-P., Kirchengast, G., Borsche, M. W., Foelsche, U., Steiner, A. K., Healy, S., von Engeln, A., O'Clerigh, E., and Marquardt, E.: Prospects of the EPS GRAS mission for operational atmospheric applications, B. Am. Meteorol. Soc., 89, 1863-1875, doi:10.1175/2008BAMS2399.1, 2008.

Melbourne, W. G., Davis, E. S., Duncan, C. B., Hajj, G. A., Hardy, K. R., Kursinski, E. R., Meehan, T. K., Young, L. E., and Yunck, T. P.: The Application of Spaceborne GPS to Atmospheric Limb Sounding and Global Change Monitoring, NASA/JPL, JPL Publ. 94-18, Pasadena, CA, 1994.
Phinney, R. A. and Anderson, D. L.: On the radio occultation method for studying planetary atmospheres, J. Geophys. Res., 73, 1819-1827, doi:10.1029/JA073i005p01819, 1968.

Ramsauer, J. and Kirchengast, G.: End-to-End GNSS Occultation Performance Simulator version 3 (EGOPS3) Software User Manual, Tech. Rep. ESA/ESTEC 1/2000, Inst. for Geophys., Astrophys., and Meteorol., Univ. of Graz, Graz, Austria, 2000.

Rothman, L. S., Jacquemart, D., Barbe, A., Chris Benner, D., Birk, M., Brown, L. R., Carleer, M. R., Chackerian Jr., C., Chance, K., Coudert, L. H., Dana, V., Devi, V. M., Flaud, J.-M., Gamache, R. R., Goldman, A., Hartmann, J.-M., Jucks, K. W., Maki, A. G., Mandin, J.-Y., Massie, S. T., Orphal, J., Perrin, A., Rinsland, C. P., Smith, M. A. H., Tennyson, J., Tolchenov, R. N., Toth, R. A., Vander Auwera, J., Varanasi, P., and Wagner, G.: The HITRAN 2004 molecular spectroscopic database, J. Quant. Spectrosc. Ra., 96, 139-204, doi:10.1016/j.jqsrt.2004.10.008, 2005.

Salby, M. L.: Fundamentals of atmospheric Physics, Academic Press, vol. 61, San Diego, 1996.

Scherllin-Pirscher, B., Steiner, A. K., Kirchengast, G., Kuo, Y.-H., and Foelsche, U.: Empirical analysis and modeling of errors of atmospheric profiles from GPS radio occultation, Atmos. Meas. Tech., 4, 1875-1890, doi:10.5194/amt-4-1875-2011, 2011.

Schweitzer, S.: The ACCURATE concept and the infrared laser occultation technique: Mission design and assessment of retrieval performance (Ph.D. thesis), Sci. Rep. No. 34, document wcv-scirep-no34-sschweitzer-jun2010.pdf, Wegener Center Verlag, Graz, Austria, available at: http://www.wegcenter.at/wcv/ (last access: 18 April 2011), 2010.

Schweitzer, S., Kirchengast, G., and Proschek, V.: Atmospheric influences on infrared-laser signals used for occultation measurements between Low Earth Orbit satellites, Atmos. Meas. Tech. Discuss., 4, 2689-2747, doi:10.5194/amtd-4-2689-2011, 2011 a.

Schweitzer, S., Kirchengast, G., Schwärz, M., Fritzer, J. M., and Gorbunov, M. E.: Thermodynamic state retrieval from microwave occultation data and performance analysis based on end-to-end simulations, J. Geophys. Res., 116, D10301, doi:10.1029/2010JD014850, 2011b.

Smith, E. K. and Weintraub, S.: The constants in the equation for atmospheric refractive index at radio frequencies, in: Proceedings of the I. R. E., 1035-1037, 1953.

Sofieva, V. F. and Kyrölä, E.: Abel integral inversion in occultation measurements, in: Occultations for Probing Atmosphere and Climate, edited by: Kirchengast, G., Foelsche, U., and Steiner, A. K., Springer Verlag, Berlin-Heidelberg, 2004.

Steiner, A. K. and Kirchengast, G.: Error analysis for GNSS radio occultation data based on ensembles of profiles from end-to-end simulations, J. Geophys. Res., 110, D15307, doi:10.1029/2004JD005251, 2005.

Steiner, A. K., Kirchengast, G., and Ladreiter, H. P.: Inversion, error analysis, and validation of GPS/MET occultation data, Ann. Geophysicae, 17, 122-138, 1999.

Steiner, A. K., Kirchengast, G., Foelsche, U., Kornblueh, L., Manzini, E., and Bengtsson, L.: GNSS occultation sounding for climate monitoring, Phys. Chem. Earth A, 26, 113-124, 2001.

Steiner, A. K., Kirchengast, G., Lackner, B. C., Pirscher, B., Borsche, M. W., and Foelsche, U.: Atmospheric temperature change detection with GPS radio occultation 1995 to 2008, Geophys. Res. Lett., 36, L18702, doi:10.1029/2009GL039777, 2009. 
Syndergaard, S.: Retrieval analysis and methodologies in atmospheric limb sounding using the GNSS radio occultation technique (Ph.D. thesis), Sci. Rep. 99-6, Danish Meteorol. Inst. Copenhagen, Denmark, 1999.

Thayer, G. D.: An improved equation for the radio refractive index of air, Radio Sci., 9, 803-807, 1974.
Ware, R., Exner, M., Feng, D., Gorbunov, M. E., Hardy, K., Herman, B. M., Kuo, W., Meehan, T., Melbourne, W., Rocken, C., Schreiner, W., Sokolovskiy, S., Solheim, F., Zou, X., Anthes, R., Businger, S., and Trenberth, K.: GPS sounding of the atmosphere from low Earth orbit: Preliminary results, B. Am. Meteorol. Soc., 77, 19-40, 1996. 